\title{
Interhemispheric asymmetries in the occurrence of magnetically conjugate sub-auroral polarisation streams
}

\author{
M. L. Parkinson ${ }^{1}$, M. Pinnock ${ }^{2}$, J. A. Wild ${ }^{3}$, M. Lester ${ }^{3}$, T. K. Yeoman ${ }^{3}$, S. E. Milan ${ }^{3}$, H. Ye ${ }^{4}$, J. C. Devlin ${ }^{4}$, \\ H. U. Frey ${ }^{5}$, and T. Kikuchi ${ }^{6}$ \\ ${ }^{1}$ Department of Physics, La Trobe University, Victoria 3086, Australia \\ ${ }^{2}$ British Antarctic Survey, Natural Environment Research Council, Cambridge CB3 OET, UK \\ ${ }^{3}$ Department of Physics and Astronomy, University of Leicester, Leicester LE1 7RH, UK \\ ${ }^{4}$ Department of Electronic Engineering, La Trobe University, Victoria 3086, Australia \\ ${ }^{5}$ Space Sciences Laboratory, University of California, Berkeley, CA 94720-7450, USA \\ ${ }^{6}$ Communications Research Laboratory, 4-2-1 Nukuikita, Koganei, Tokyo 184-8795, Japan
}

Received: 2 April 2004 - Revised: 1 March 2005 - Accepted: 22 March 2005 - Published: 3 June 2005

\begin{abstract}
Earthward injections of energetic ions and electrons mark the onset of magnetospheric substorms. In the inner magnetosphere $(\mathrm{L} \sim 4)$, the energetic ions drift westward and the electrons eastward, thereby enhancing the equatorial ring current. Wave-particle interactions can accelerate these particles to radiation belt energies. The ions are injected slightly closer to Earth in the pre-midnight sector, leading to the formation of a radial polarisation field in the inner

board the IMAGE spacecraft. DMSP SSIES ion drift measurements confirmed the presence of AWFCs equatorward of the auroral oval. Systematic asymmetries in the interhemispheric signatures of the AWFCs probably arose because the magnetic flux tubes were distorted at $\mathrm{L}$ shells passing close to the substorm dipolarisation region. Transient asymmetries were attributed to the development of nearby field-aligned potential drops and currents.
\end{abstract} magnetosphere. This maps to a poleward electric field just equatorward of the auroral oval in the ionosphere. The poleward electric field is subsequently amplified by ionospheric feedback, thereby producing auroral westward flow channels (AWFCs). In terms of electric field strength, AWFCs are the strongest manifestation of substorms in the ionosphere. Because geomagnetic flux tubes are essentially equi-potentials, similar AWFC signatures should be observed simultaneously in the Northern and Southern Hemispheres. Here we present magnetically conjugate SuperDARN radar observations of AWFC activity observed in the pre-midnight sector during two substorm intervals including multiple onsets during the evening of 30 November 2002. The Northern Hemisphere observations were made with the Japanese radar located at King Salmon, Alaska $\left(57^{\circ} \Lambda\right)$, and the Southern Hemisphere observations with the Tasman International Geospace Environment Radar (TIGER) located at Bruny Island, Tasmania $\left(-55^{\circ} \Lambda\right)$. LANL geosynchronous satellite observations of energetic ion and electron fluxes monitored the effects of substorms in the inner magnetosphere $(\mathrm{L} \sim 6)$. The radarobserved AWFC activity was coincident with activity observed at geosynchronous orbit, as well as westward current surges in the ionosphere observed using ground-based magnetometers. The location of AWFCs with respect to the auroral oval was inferred from FUV auroral images recorded on

Correspondence to: M. L. Parkinson

(m.parkinson@latrobe.edu.au)
Keywords. Ionosphere (Auroral ionosphere; Electric fields and currents; Ionosphere-magnetosphere interactions) Magnetospheric physics (Storms and substorms)

\section{Introduction}

Bursty reconnection (Russell and Elphic, 1978; Haerendel et al., 1978) of solar and terrestrial magnetic fields is thought to drive the flow of plasma across the open-closed magnetic field-line boundary (OCB) in the high-latitude ionosphere (Cowley and Lockwood, 1992). Due to the incompressibility of the ionosphere, the flow bursts generate a characteristic circulation pattern which extends across the polar cap and auroral oval. The convection reversal boundary (CRB) is approximately aligned with the OCB. Here we will refer to the flow reversal boundary (FRB) which represents an equatorward limit to the reconnection driven circulation, and marks the transition to approximately corotational flows of the midlatitude ionosphere (Huang et al., 2001). Although reconnection driven circulation can penetrate across the FRB, is there some other fundamental driver of magnetospheric circulation mapping to the auroral and sub-auroral ionosphere?

Polarisation Jets (PJs) (Galperin et al., 1973) are narrow channels $\left(<1\right.$ to $\left.2^{\circ} \Lambda\right)$ of intense westward plasma flow $\left(\sim 1 \mathrm{~km} \mathrm{~s}^{-1}\right.$ to $\left.>4 \mathrm{~km} \mathrm{~s}^{-1}\right)$ which occur just equatorward of, or overlapping, the equatorward edge of the auroral oval. 
Their peak occurrence is in the evening sector near $22 \mathrm{~h}$ magnetic local time (MLT) (Karlsson et al., 1998). They are also known as sub-auroral ion drift events (SAIDs) (Spiro et al., 1979) and sub-auroral electric fields (SAEFs) (Karlsson et al., 1998). Important satellite (Smiddy et al., 1977; Rich et al., 1980; Anderson et al., 1991, 1993, 2001) and radar (Galperin et al., 1986; Providakes et al., 1989; Yeh et al., 1991) observations have been reported. Substorm-associated radar auroral surges (SARAS) (Freeman et al., 1992; Shand et al., 1998) and auroral westward flow channels (AWFCs) (Parkinson et al., 2003) are probably different aspects of the same underlying phenomenon.

Recently, a more encompassing term, the "subauroral polarisation stream" (SAPS) (Foster and Burke, 2002), has been proposed. This term is so useful because it helps to describe the weaker background westward flows ( $\sim 100$ to $\left.400 \mathrm{~m} \mathrm{~s}^{-1}\right)$ persisting beyond midnight, and during quieter conditions, which help to define the FRB. PJ/SAIDs can be thought of as enhanced SAPS flows or as discrete events within the SAPS. Perhaps PJ/SAIDs ultimately drive the SAPS and the equatorward limit of the return sunward flow within the evening convection cell, as well as structure within that flow.

A qualitative theory of PJ/SAID formation and evolution has emerged from observations (i.e. above) and theoretical considerations (Southward, 1977, 1978; De Keyser et al., 1998; De Keyser, 1999; Galperin, 2002). Basically, during magnetospheric storms and near to the onset of substorms, an "injection front" of energetic ions and electrons forms in the magnetotail and migrates Earthward toward ring current/radiation belt L shells ( $\sim 4$ to 5 ). Substorm physics and the associated Earthward injections are thought to result from an explosion of magnetic reconnection near $\sim 25 R_{E}$ in the late growth phase (Baker et al., 1999), or an instabilitytriggered reconfiguration of the inner magnetosphere in the current disruption model (Lui, 2001), or both.

Energetic ions and electrons within the injection front are driven Earthward by an enhanced cross-tail electric field. Ions subsequently drift westward and electrons eastward under the influence of gradient and curvature drifts, thereby contributing to the familiar ring current. The trajectory of the ions extend closer to Earth than the electrons pre-midnight (and vice versa post-midnight). This seeds the initial formation of a weak space-charge separation; thus radial polarisation fields develop in the inner magnetosphere.

The high-latitude ionosphere may play a crucial role in the evolution of magnetospheric features. Because the Earth's magnetic field lines are approximately equi-potentials, an initial, weak radial polarisation field in the magnetosphere will map to a poleward directed electric field in the ionosphere of both hemispheres. Electric fields are thought to avoid regions of large height-integrated Pedersen conductivity $\left(\Sigma_{p}\right)$, but they are focussed into regions of low $\Sigma_{p}$ (e.g. Milan et al., 1999). This must occur because Pedersen currents would otherwise lead to the accumulation of space charge at the boundaries between low and high $\Sigma_{p}$.

In the case of PJ/SAIDs, the poleward directed electric field maps to the main ionospheric trough, a region of rel- atively low $\Sigma_{p}$. Application of $\boldsymbol{E}=-\boldsymbol{v} \times \boldsymbol{B}$ implies a rapid, westward flow of plasma within the plasma trough. Ionneutral frictional heating is then thought to further reduce the plasma density, which also reduces $\Sigma_{p}$, which in turn leads to an amplification of the initial polarisation field $\left(\boldsymbol{J}_{\boldsymbol{p}}=\Sigma_{p} \boldsymbol{E}\right)$. Thus a run-away effect may lead to an intensification of the magnetospheric field, resulting in some very large ionospheric westward drifts $\left(>4 \mathrm{~km} \mathrm{~s}^{-1}\right)$. Of course, this model assumes a steady magnetospheric current source which is strictly not true given the finite lifetime of PJ/SAIDs ( $\sim 1$ to $3 \mathrm{~h})$.

In the preceding description of coupled feedback, we do not mean to imply that PJ/SAIDs are driven by the magnetosphere, or that polarisation fields in the magnetosphere are driven by the ionosphere. Rather, both act in unison. For example, the presence of a pre-existing ionospheric trough might amplify a magnetospheric perturbation which would otherwise stabilise. Conversely, an ionospheric perturbation might not develop without an initial magnetospheric perturbation. The temporal history of all the substorm elements is still an open question.

More detailed modelling and theory, combined with more comprehensive observations, are required. For example, the preference for PJ/SAIDs to occur pre-midnight is thought to arise from the opposing effect of a relatively weak corotation field (De Keyser et al., 1998). It is also uncertain how the field-aligned current sheets at the equatorward $(\boldsymbol{J}$ downward) and poleward ( $\boldsymbol{J}$ upward) edges of PJ/SAIDs are driven and sustained. Richard Horne (Private Communication) is working on a substorm model of wave-particle interactions which may scatter a sufficient number of charge carriers into the loss cone to account for the required current densities $\left(\sim 1 \mu \mathrm{A} \mathrm{m}^{-2}\right)$.

Parkinson et al. (2003) reported radar observations of a single AWFC. The characteristics of this event were similar to those of PJ/SAIDs, except it grew and decayed with the onset and recovery of a moderate substorm, respectively. Burke et al. (2000) also reported a PJ/SAID during the expansion phase of a geomagnetic substorm. This contrasts with previous satellite observations reporting the exclusive occurrence of PJ/SAIDs during substorm recovery phase (Anderson et al. 1993; Karlsson et al., 1998).

Observations reported by Parkinson et al. (2003) were also noteworthy because they showed the AWFC was the primary signature of the substorm in terms of the strength of ionospheric and magnetospheric electric fields. This contrasts with ground-based magnetometer observations which respond to ionospheric Hall currents at high latitudes. These observations have long shown the ionospheric substorm is located further poleward in the highly conducting discrete auroral oval. Recent radar observations have also revealed the suppression of substorm electric fields in the auroral oval (Provan et al., 2004).

We have introduced the basic picture of PJ/SAID formation and evolution. We need to question every aspect of this picture with new, comprehensive observations. General conclusions about a phenomenon should not be made on the 


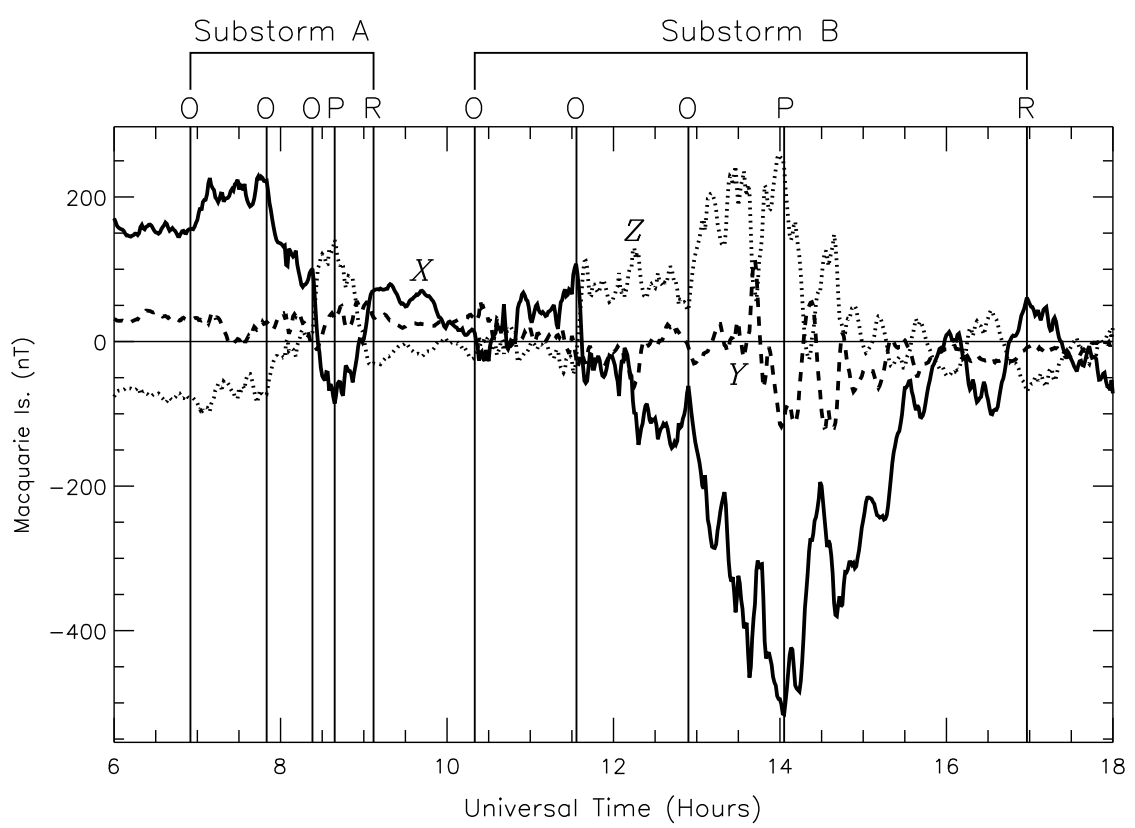

Fig. 1. Perturbations of the geomagnetic $X$ (solid curve), $Y$ (dashed curve), and $Z$ (dotted curve) components measured by the MQI magnetometer during 06:00 to 18:00 UT on 30 November 2002. Annotations indicate approximate times of substorm onset (O), peak expansion (P), and end of recovery phase (R). The abscissa has tick marks at 30-min intervals of UT.

basis of a limited number of events observed using the same technique. It is not even clear whether PJ/SAIDs and AWFC are the same phenomenon. For example, the AWFC reported by Parkinson et al. (2003) started near, and might have been a trigger for, substorm expansion. Other radar observations may ultimately show that AWFCs can commence during the growth or recovery phase, and even during geomagnetic quiet conditions.

In this paper, we further investigate the behaviour of an AWFC and SAPS observed concurrently by two magnetically conjugate radars. The present observations will enable us to further define the characteristics of AWFCs, as well as test whether the different behaviour observed in opposite hemispheres can be reconciled with the notion that geomagnetic field lines are equi-potentials. We believe our AWFC observations help to challenge and refine existing models of substorms and PJ/SAIDs.

\section{Instruments}

In this study we report magnetically conjugate HF radar observations recorded during the night of 30 November 2002. The interpretation of these observations will be supported by measurements made by various instruments including:

1. The Advanced Composition Explorer (ACE) spacecraft was located at geocentric solar magnetospheric $(X, Y$, $Z)$ co-ordinates of $(239.2,26.5,-11.8) R_{E}$ during the study interval. We report ACE magnetometer (Smith et al., 1998) observations of the interplanetary magnetic field (IMF).
2. A fluxgate magnetometer is located on Macquarie Is. (MQI) $\left(54.5^{\circ} \mathrm{S}, 158.9^{\circ} \mathrm{E} ;-65^{\circ} \Lambda\right)$, and provides the most direct indication of Hall current flow (Fig. 1) in proximity to the radars (Fig. 4). Perturbations in geodetic co-ordinates were transformed to perturbations in the geomagnetic $X$ (North), $Y$ (East), and $Z$ (down) directions. These components were de-spiked and then de-trended by subtracting a baseline defined by averaging their values over day numbers 332 to 336 which included 30 November and adjacent quiet intervals.

3. The Los Alamos National Laboratory (LANL) satellites are in geosynchronous, equatorial orbits of radius 6.6 $R_{E}$. The Synchronous Orbit Particle Analyzers (SOPA) measure the spin-averaged differential flux of energetic electrons in 16 energy channels between $50 \mathrm{KeV}$ and $26 \mathrm{MeV}$ and protons in 15 energy channels between $50 \mathrm{KeV}$ and $>50 \mathrm{MeV}$. Decreases in particle fluxes can occur because magnetic flux tubes stretch during the growth phase of substorms. Subsequent dispersionless increases in particle flux signify the time (UT) and location (MLT) of substorm particle injections (Henderson et al., 1996).

4. The uniform design and operation of Super Dual Auroral Radar Network (SuperDARN) radars has been described by Greenwald et al. (1985, 1995). Standard parameters returned by the "FITACF" algorithm (Baker et al., 1995) used to analyse echoes in real time include the backscatter power (dB), line-of-sight (LOS) Doppler velocity $\left(\mathrm{m} \mathrm{s}^{-1}\right)$, and Doppler spectral width $\left(\mathrm{m} \mathrm{s}^{-1}\right)$. The spectral widths are a measure of the life 

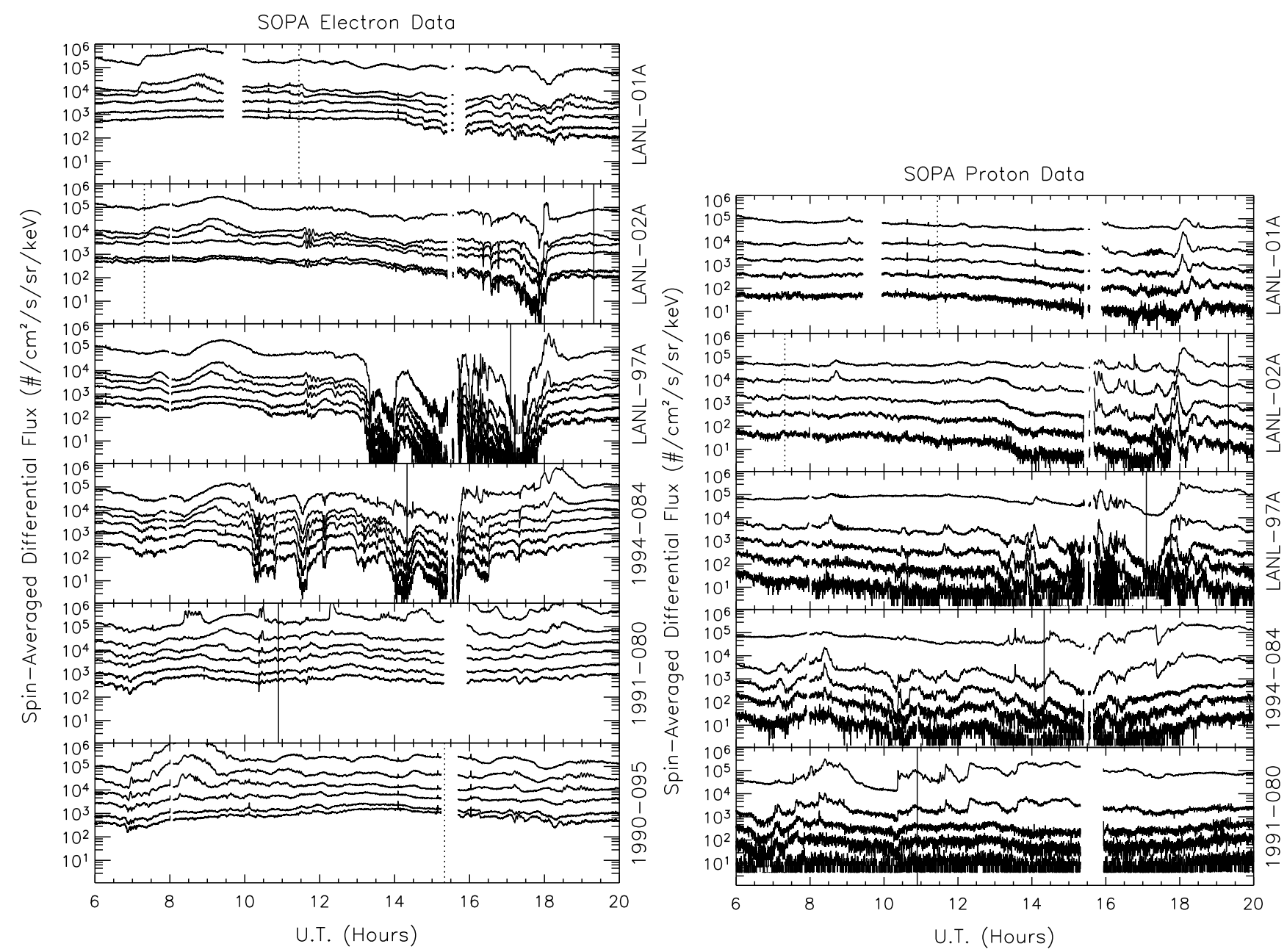

Fig. 2. (a) LANL SOPA spectra of spin-averaged differential electron fluxes measured at geosynchronous orbit during 06:00 to 20:00 UT, 30 November 2002. Each panel shows the results for a different satellite located at a different longitude. Continuous (dotted) vertical lines indicate when a satellite was located at local midnight (noon). The differential fluxes are shown on a logarithmic scale, with separate curves for each energy channel: $50-75 \mathrm{KeV}$ (top), $75-105 \mathrm{KeV}, 105-150 \mathrm{KeV}, 150-225 \mathrm{KeV}, 225-315 \mathrm{KeV}$, and 315-500 KeV (bottom) (b) The same except for the proton fluxes, with separate curves for each energy channel: $50-75 \mathrm{KeV}$ (top), $75-113 \mathrm{KeV}, 113-170 \mathrm{KeV}$, $170-250 \mathrm{KeV}$, and $250-400 \mathrm{KeV}$ (bottom)

time of ionospheric irregularities, and space and time variations in the LOS Doppler velocity occurring within the sampling volume and integration time. As reviewed by André et al. (2000), the spectral widths might be enhanced by electric field variations in the Pc 1-2 frequency range, micro-scale $(\sim 10 \mathrm{~m})$ plasma turbulence, and non-uniform convection flows from small $(\sim 1 \mathrm{~km})$ to large scales $(\sim 1000 \mathrm{~km})$.

A SuperDARN radar is operated by the Communications Research Laboratory, Japan, at King Salmon, Alaska $\left(58.7^{\circ} \mathrm{N}, 203.4^{\circ} \mathrm{E} ; 57^{\circ} \Lambda\right)$ (KGS hereafter). The relatively low magnetic latitude and zonal looking fieldof-view (FOV) of KGS (Fig. 4a) favours detection of large westward flows in AWFCs. During the study interval, KGS performed one full scan every 2 min using $6 \mathrm{~s}$ integrations sequentially from beam 15 (east) to 0 (west). It mostly operated in the "fixed" frequency band 10.2 to $10.9 \mathrm{MHz}$.

The Tasman International Geospace Environment Radar (TIGER) (Dyson and Devlin, 2000) is located on Bruny Is., Tasmania $\left(43.4^{\circ} \mathrm{S}, 147.2^{\circ} \mathrm{E} ; 55^{\circ} \Lambda\right)$. TIGER beam 15 , the eastern-most beam, is very sensitive to the detection of AWFCs (Parkinson et al., 2003) because it becomes a magnetic zonal beam at furthest ranges. TIGER performed one full scan every 1 min using 3 $\mathrm{s}$ integrations sequentially from beam 15 to 0 . During 07:30 to $08: 08$ and $10: 25$ to $14: 30$ UT, it operated in the frequency band 9.5 to $9.9 \mathrm{MHz}$. During 08:09 to 08:54 UT it operated in the band 17.8 to $17.9 \mathrm{MHz}$, and during 08:55 to 10:24 UT, it operated in the band 14.5 to $14.9 \mathrm{MHz}$. 
5. The Imager for Magnetopause to Aurora Global Exploration (IMAGE) satellite is in a polar orbit with apogee $7.2 R_{E}$ and perigee $1000 \mathrm{~km}$. During the evening of 30 November, IMAGE made observations of the Northern Hemisphere. The Wideband Imaging Camera (WIC) (Mende et al., 2000) provides global far ultraviolet (FUV) images of the aurora by detecting broadband emissions from the Lyman-Birge-Hopefield $\mathrm{N}_{2}$ transitions. In practice, WIC images provided an indication of the energy flux of precipitating $\mathrm{KeV}$ electrons (Mende et al., 2001), and thus also regions of enhanced ionospheric conductivity. WIC images were recorded once every $2 \mathrm{~min}$, the spin period of IMAGE, and they were mapped to the same co-ordinates as the radar observations. Frey et al. (2001) discussed calibration of WIC counts.

6. The Defence Meteorological Satellite Program (DMSP) satellites are near polar orbiting, Sun synchronous satellites. They have an altitude of $830 \mathrm{~km}$ and an orbital period of $101 \mathrm{~min}$. The SS J/4 detectors (Hardy et al., 1984) measure precipitating ions and electrons every second from which spectra of differential energy flux $\left(\mathrm{eV} \mathrm{cm}^{-2} \mathrm{~s}^{-1} \mathrm{sr}^{-1} \mathrm{eV}^{-1}\right)$ are calculated. The spectra span the energy range $30 \mathrm{eV}$ to $30 \mathrm{KeV}$. We made use of online energy spectrograms and nightside auroral oval boundaries automatically identified using the logical criteria outlined by Newell et al. (1996).

The Special Sensor-Ions, Electrons, and Scintillation (SSIES) instruments on board the DMSP satellites consist of retarding potential analysers, drift meters, Langmuir probes, and scintillation meters. They provide measurements of various parameters including plasma density and ion drift velocity transverse $\left(V_{y}\right)$ to the satellite trajectory. Here we utilise $V_{y}$ measured at 4-s resolution during favourable conjunctions with the radars.

Observations made by the different instruments were compared using altitude adjusted corrected geomagnetic coordinates (AACGM) (Baker and Wing, 1989). Observations made with the two HF radars were mapped using the same standard procedures (Yeoman et al., 1999). Small errors $\left(<0.5^{\circ} \Lambda\right)$ in the registration of radar and DMSP observations were minimised by re-calculating the DMSP co-ordinates using the same AACGM algorithm.

\section{Observations and analysis}

ACE spacecraft measurements of the IMF during 30 November 2002 showed that $B_{x}$ was approximately $-5 \mathrm{nT}$, though fluctuating between -8 and $+6 \mathrm{nT}$. Similarly, $B_{y}$ was approximately $+5 \mathrm{nT}$, though fluctuating between -6 and $+8 \mathrm{nT}$. Again, $B_{z}$ was approximately $-4 \mathrm{nT}$, though fluctuating between -7 and $+6 \mathrm{nT}$. A noteworthy $B_{z}$ southward transition occurred at 12:40 UT. In summary, despite numerous fluctuations in all three IMF components, $B_{x}$ was mostly neg-

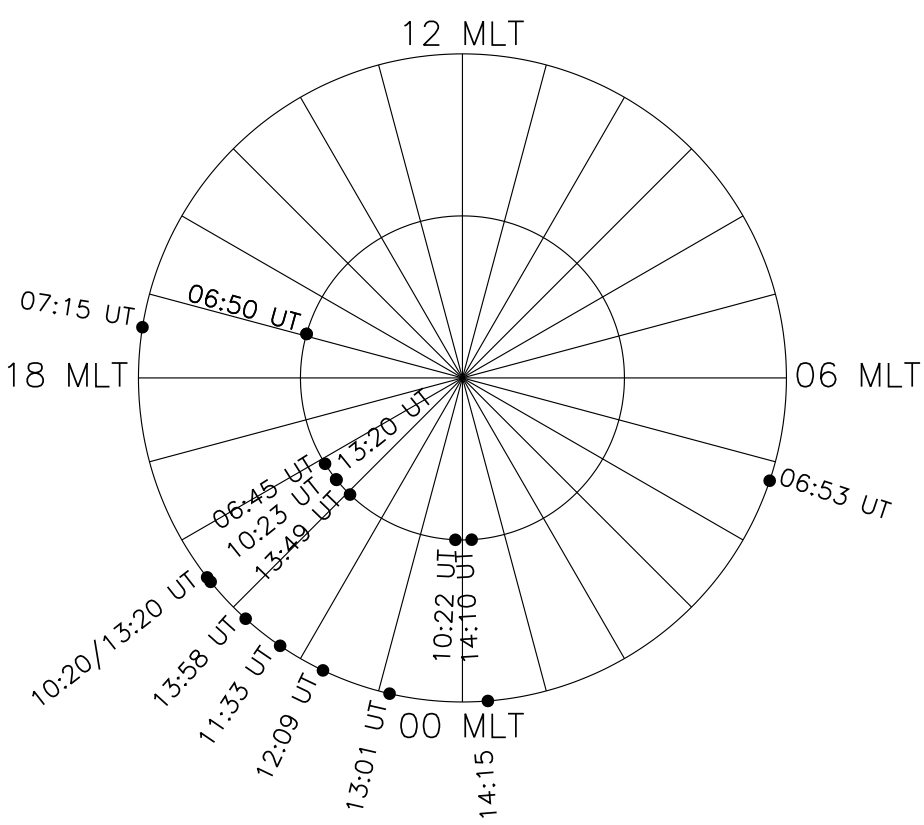

Fig. 3. The universal time (UT) and magnetic local time (MLT) of ion flux decreases (inner circle) and electron flux decreases (outer circle) measured on board the LANL geosynchronous satellites during the evening of 30 November 2002. These timings are also listed in Table 1.

ative, $B_{y}$ was mostly positive, and $B_{z}$ was mostly negative. There were no major discontinuities in the solar-wind dynamic pressure.

\subsection{Ground-based magnetometer observations}

MQI fluxgate magnetometer data are shown in Fig. 1. A positive bay in the geomagnetic $X$ component commenced near 06:55 UT, the start of a substantial substorm. MQI was located near 18:41 MLT and so, as expected, a positive bay corresponding to an enhanced eastward electrojet was observed. As MQI rotated further toward the east it eventually came under the influence of the westward electrojet which may have also expanded westward. MQI recorded negative onset-like (O) signatures at 07:50 and 08:23 UT, a peak expansion phase $(\mathrm{P})$ at 08:39 UT, and the nominal end of recovery phase (R) at 09:07 UT. The earliest signature of a second substorm was a small negative bay commencing at 10:27 UT. Subsequent expansion signatures commenced near 11:33 and 12:54 UT. Peak expansion phase was observed at 14:03 UT, and the nominal end of recovery phase was 16:58 UT.

These onset times are similar to, but slightly later, than those measured by the CANOPUS magnetometer array located further to the east in the Northern Hemisphere. Negative bays in the geodetic $X$ component were consistent with the first substorm having an onset near 06:55 UT, and a subsequent peak expansion of $\sim 700 \mathrm{nT}$ near 08:20 UT. The second substorm was also revealed by ongoing negative deflections commencing near $\sim 10: 20$ UT. The magnetometer data were complicated because they suggested the occurrence of 

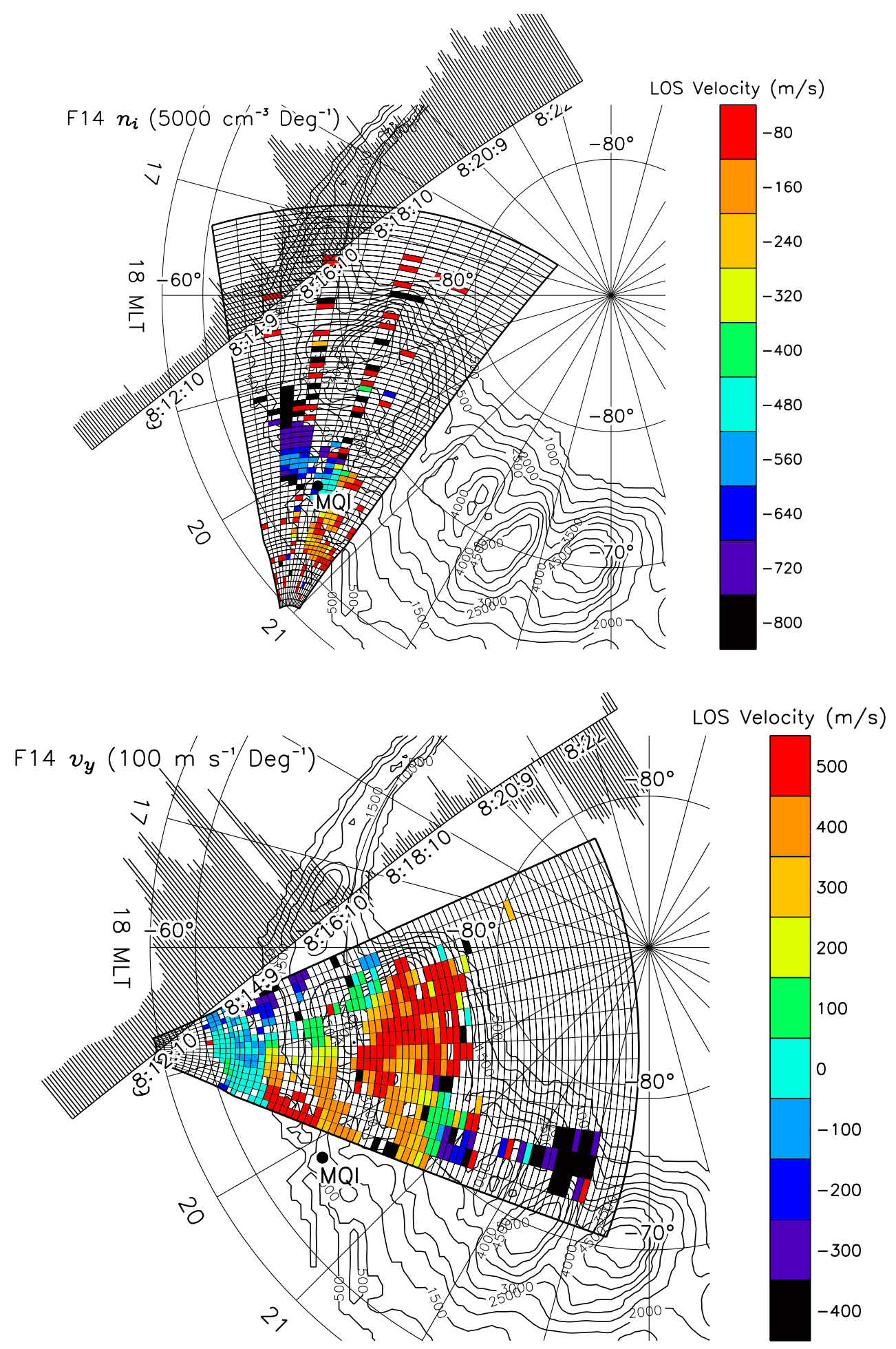

Fig. 4. (a) King Salmon (KGS) radar observations of the LOS Doppler velocity measured during the full scan commencing at 08:15:59 UT on 30 November 2002. The colour key means the colour orange, for example, corresponds to all velocities in the range $-200<v_{L} O S \leq-120 \mathrm{~m} \mathrm{~s}^{-1}$. DMSP F14 measurements of ion density at 4-s resolution have been superimposed along the satellite trajectory using a transverse scale of 5000 ions $\mathrm{cm}^{-3}$ per degree of magnetic latitude $\left({ }^{\circ} \Lambda\right)$. (b) TIGER radar observations of the same, except for the full scan commencing at 08:15:00 UT. DMSP F14 measurements of ion drift velocity transverse to the satellite trajectory, $V_{y}$, have been superimposed using a scale of $100 \mathrm{~m} \mathrm{~s}^{-1} \circ \Lambda^{-1}$. The background contours show variations of far ultraviolet (FUV) auroral emissions recorded by the IMAGE WIC experiment at 08:15:54 UT. 
multiple onsets during two substorm intervals. As shown in Fig. 1, we shall refer to these two major, broad intervals as "Substorm A" and "Substorm B."

The provisional $D_{s t}$ index decreased from $-14 \mathrm{nT}$ at $7 \mathrm{UT}$ to $-37 \mathrm{nT}$ at $15 \mathrm{UT}$.

\subsection{LANL Geosynchronous satellite observations}

Figure 2a shows all the LANL SOPA spectra of spinaveraged differential electron fluxes made during 06:00 to 20:00 UT on 30 November 2002. Figure $2 b$ shows the same except for protons. To reduce clutter, particle fluxes are only shown for the six lowest energy channels for electrons and the five lowest energy channels for protons. Table 1 lists the estimated times of energetic particle flux decreases most relevant to our coincident radar observations, and Fig. 3 summarises the timings for low energy ions (inner circle) and electrons (outer circle). Note that (1) whilst most flux decreases and subsequent increases were probably indicative of substorm-related particle injections, this is not necessarily the case, and (2) the geosynchronous orbits of LANL satellites map to magnetic latitude $\sim 66.5^{\circ} \Lambda$, or 2 to $3^{\circ}$ poleward of the AWFCs detected by the radars.

Satellite 1991-080 was located near dusk when it observed a decrease in proton flux at 06:45 UT (Fig. 2b, panel 5). Satellite 1990-095 (Fig. 2a, panel 6) was located near dawn when it measured a weak decrease in electron flux at $\sim 06: 53$ UT. Satellite 1994-084 was located near dusk when it measured a weak decrease in electron flux at $\sim 07: 15 \mathrm{UT}$, and proton flux at 06:50 UT . The broad peaks in electron flux observed by all satellites between $\sim 08$ and 10 UT may represent a continuation of the injection commencing just prior to 07 UT. This becomes apparent when the fluxes in higher energy channels (not shown) are examined.

A more intense sequence of activity commenced after 10 UT. Satellite 1994-084 (Fig. 2a, panel 4) was located from late evening to just past magnetic midnight when it recorded considerable activity from 10 to $17 \mathrm{~h}$ UT. As Table 1 lists, substantial decreases in electron flux, followed by fairly sudden increases across many energy channels, were observed at $\sim 10: 20,11: 33,12: 09,13: 01,14: 15 \mathrm{UT}$, and at other times beyond our radar observations. Table 1 lists the corresponding magnetic local times (MLTs) of these observations.

Satellite LANL-97A (Fig. 2a, panel 3) was located $\sim 3 \mathrm{~h}$ earlier in the evening sector when substantial decreases in electron flux were observed at $\sim 13: 20,13: 58 \mathrm{UT}$, and more afterwards. Low energy proton measurements made by satellite 1994-084 (Fig. 2b, panel 4) suggest the entire interval 6 to $19 \mathrm{~h}$ UT was active. Substantial decreases in proton flux were observed at 10:23, 14:10 UT, and at various other times. Similarily, the satellite LANL-97A observed substantial decreases at $\sim 13: 20,13: 49$ UT, and more afterwards. Satellite 1991-080 (panel 5) was located close to midnight when it observed a decrease in proton flux at $\sim 10: 22$ UT.

In summary, these complicated LANL energy spectra provided important information about changes in the outer radi-
Table 1. LANL SOPA measurements of energetic particle flux decreases, 30 November 2002.

\begin{tabular}{llll}
\hline Satellite & U.T. & M.L.T. & E/P \\
\hline 1991-080 & $06: 45$ & $20: 08$ & $\mathrm{P}^{*}$ \\
1994-084 & $06: 50$ & $16: 57$ & $\mathrm{P}$ \\
1990-095 & $06: 53$ & $04: 46$ & $\mathrm{E}$ \\
1994-084 & $07: 15$ & $17: 24$ & $\mathrm{E}$ \\
1994-084 & $10: 20$ & $20: 32$ & $\mathrm{E}^{*}$ \\
1991-080 & $10: 22$ & $23: 50$ & $\mathrm{P}$ \\
1994-084 & $10: 23$ & $20: 35$ & $\mathrm{P}^{*}$ \\
1994-084 & $11: 33$ & $21: 42$ & $\mathrm{E}^{*}$ \\
1994-084 & $12: 09$ & $22: 18$ & $\mathrm{E}$ \\
1994-084 & $13: 01$ & $23: 08$ & $\mathrm{E}$ \\
1994-084 & $14: 10$ & $00: 13$ & $\mathrm{P}^{*}$ \\
1994-084 & $14: 15$ & $00: 18$ & $\mathrm{E}^{*}$ \\
1994-084 & $13: 20$ & $20: 36$ & $\mathrm{P}^{*}$ \\
LANL-97A & $13: 20$ & $20: 36$ & $\mathrm{E}$ \\
1994-084 & $13: 49$ & $21: 04$ & $\mathrm{P}^{*}$ \\
LANL-97A & $13: 58$ & $21: 12$ & $\mathrm{E}^{*}$ \\
\hline
\end{tabular}

${ }^{1}$ E: Electrons, P: Protons

* Most significant decreases

ation belt including the effects of multiple particle injections. By analysing the results plotted graphically in Fig. 2, they can be partly reconciled with the familiar eastward (westward) drift of electrons (protons) in the outer ring current. For example, $1-\mathrm{MeV}$ protons have an orbital period in the order of $\sim 7$ min at $\mathrm{L}=6$, this period increasing by a full order for $100-\mathrm{KeV}$ particles. The periods are slightly longer for electrons.

Although the exact sequence of radiation belt events is difficult to decipher due to the multiple onsets and injections, the LANL results are basically consistent with groundbased magnetograms which show the onset of a substantial substorm shortly after $\sim 06: 45$ UT (Substorm A), and at $\sim$ 10:20 UT (Substorm B).

3.3 Full-scan radar observations and coincident satellite observations

The following full-scan observations are shown because of their good coincidence in space and time with the trajectory of the DMSP F14 satellite, and because they were representative of other observations. Reproducing all the one- or two-minute resolution full-scan plots would be impractical. Note that all data have been mapped to a "clock dial" consisting of MLT and magnetic latitude, and echoes identified as "ground scatter" by FITACF have been excluded.

Figure 4a shows KGS radar observations of LOS Doppler velocity for the full-scan commencing at 08:15:59 UT. Figure $4 \mathrm{~b}$ shows TIGER observations of the same, except for the full-scan commencing at 08:15:00 UT. The full-scan observations were separated in this way because otherwise the coloured pixels overlap and become illegible. Note the 
colour scale used for KGS velocities in Fig. 4a was shifted toward large negative values (i.e. receding toward the west), whereas the colour scale used for TIGER velocities was shifted toward moderate positive values (i.e. approaching toward the east). These Doppler shifts are consistent with the orientation of the radar FOVs with respect to an AWFC.

The background contours show variations in WIC FUV auroral counts in the Northern Hemisphere recorded on board the IMAGE satellite at 08:15:54 UT. These counts were mapped to the Southern Hemisphere (Fig. 4b) simply by inverting their magnetic latitudes. These FUV emissions were recorded well past the earliest onset signatures of Substorm A (06:55 and 07:50 UT); hence the extensive latitudinal width of the auroral oval. Comparing this image with the previous WIC image at 08:13:50 UT shows a rapid poleward and westward surge toward dusk had just occurred.

DMSP SSIES measurements were made on board the F14 satellite which traversed the Northern Hemisphere through the western-most part of the KGS radar FOV during 08:14 to $08: 18 \mathrm{UT}$. The footprint of the spacecraft was $\sim 1 \mathrm{~h}$ to the west of the main patch of scatter detected by both KGS and TIGER. Note that F14 measurements may have systematic errors due to failure of the electronics used to negate the effects of spacecraft charging. Hence these offsets will be greatest for dayside measurements. Nevertheless, the F14 results were similar to those obtained by the F13 and F15 satellites, and are consistent with the interpretation of the radar observations.

Figure 4a includes SSIES measurements of ion density at 4-s resolution superimposed along the satellite trajectory using a transverse scale of 5000 ions $\mathrm{cm}^{-3}$ per degree of magnetic latitude $\left({ }^{\circ} \Lambda\right)$. Although made further to the west and in the topside ionosphere, these measurements suggest the AWFC may have been centred near a localised trough in ion density of $\sim 9200 \mathrm{~cm}^{-3}$ located at $66.7^{\circ} \Lambda$. This contrasts with the peak ion density of $\sim 50000 \mathrm{~cm}^{-3}$ located at $70.7^{\circ} \Lambda$, near the poleward edge of the region of FUV emission (background contours).

DMSP F14 automatic nightside auroral oval boundaries were in good agreement with the location of WIC FUV emissions. During this F14 satellite pass, the equatorward edges of the electron (ion) aurora were located at $66.6^{\circ} \Lambda\left(64.5^{\circ} \Lambda\right)$, and the poleward edges of the electron (ion) aurora were located at $67.9^{\circ} \Lambda\left(71.1^{\circ} \Lambda\right)$. Online spectrograms showed enhanced fluxes of 1 to $10 \mathrm{KeV}$ electron precipitation in a narrow band centred near $67.6^{\circ} \Lambda$, close to the peak FUV emission along the track. We conclude the AWFC straddled the equatorward edge of the auroral oval.

The KGS radar recorded scatter with the LOS Doppler velocity generally increasing on the western-most beams which look toward lower latitude, and more zonally (Fig. 4a). For example, LOS velocities $<-760 \mathrm{~m} \mathrm{~s}^{-1}$ were observed on beam 3 near 19:15 MLT and $65^{\circ} \Lambda$, consistent with the presence of an AWFC. The orientation of the scatter and velocities suggest the AWFC was tilted poleward toward the west. The WIC FUV data suggest the radar scatter and AWFC overlapped diffuse auroral emissions.
Figure $4 \mathrm{~b}$ shows LOS velocities recorded by the TIGER radar in the Southern Hemisphere. TIGER recorded large approaching LOS velocities $\left(>450 \mathrm{~m} \mathrm{~s}^{-1}\right)$ on beam 15 , and large receding velocities $\left(<-350 \mathrm{~m} \mathrm{~s}^{-1}\right)$ on beam 0 , both near $-64^{\circ} \Lambda$. Hence the AWFC was located at similar latitudes in the Southern and Northern Hemispheres. However, the distribution of scatter and LOS velocities suggest that a second, weaker AWFC may have been located further poleward near $-67^{\circ} \Lambda$. Even further poleward, the LOS velocities were equatorward on nearly all beams, probably due to the LOS component of return sunward flows in a contracted afternoon convection cell.

SSIES measurements of transverse velocity, $V_{y}$, the most reliable velocity component, are superimposed in Fig. $4 \mathrm{~b}$ using a transverse scale of $100 \mathrm{~m} \mathrm{~s}^{-1} \circ \Lambda^{-1}$. The two largest peak $V_{y}$ 's of $1210 \mathrm{~m} \mathrm{~s}^{-1}$ near $63.8^{\circ} \Lambda$ and $1506 \mathrm{~m} \mathrm{~s}^{-1}$ near $66.8^{\circ} \Lambda$ were coincident in space and time with the main AWFC signatures recorded by TIGER. Likewise, a local minimum in $V_{y}$ of $205 \mathrm{~m} \mathrm{~s}^{-1}$ near $67.7^{\circ} \Lambda$ was coincident with the most intense electron precipitation identified in both DMSP and IMAGE measurements. Radar scatter also tended to be absent in these regions. The westward flows extending equatorward of the auroral oval were structured, suggesting the presence of bifurcated or multiple AWFCs imbedded within the return sunward flows. DMSP measurements reveal similar structured flow on a routine basis.

Figure 5a shows KGS observations of LOS Doppler velocity measured for a full-scan commencing much later during the evening at 11:03:59 UT. Figure 5b shows TIGER observations of the same. Again, the background contours show variations of WIC FUV counts, this time recorded at 11:04:19 UT. The preceding time sequence of WIC images revealed the poleward extension of emission located near 22:50 MLT was often far more intense earlier during Substorm B. The auroral oval was also thinner, and did not extend as far poleward as shown in Fig. 4a. Overall, the intensity of emission was lower than in Fig. 4.

A DMSP F14 satellite pass in the Southern Hemisphere, when mapped to the Northern Hemisphere, was coincident with these observations. Again, the F14 automatic nightside auroral oval boundaries agreed with the location of WIC FUV emissions. During this F14 satellite pass, the equatorward edges of the electron (ion) aurora were located at $-62.9^{\circ} \Lambda\left(-62.9^{\circ} \Lambda\right)$, and the corresponding poleward edges were located at $-68.3^{\circ} \Lambda\left(-68.6^{\circ} \Lambda\right)$. Online spectrograms showed enhanced fluxes of 1 to $10 \mathrm{KeV}$ electron precipitation commencing poleward of $-65.7^{\circ} \Lambda$, in agreement with the largest FUV counts. The KGS observations (Fig. 5a) revealed scatter with large LOS velocity $\left(<-650 \mathrm{~m} \mathrm{~s}^{-1}\right)$ concentrated on beams 0 to 5 . The magnitude of LOS velocities increased toward beam 0 , the most equatorward and zonal beam, and they also increased with group range. The speeds had maximum values $<-850 \mathrm{~m} \mathrm{~s}^{-1}$ on beam 0 at the furthest ranges. The observed Doppler characteristics, namely an increase in westward drift toward the west, combined with proximity of the scatter to midnight, imply observation of the spatial origin of the AWFC. The structure of FUV emissions 

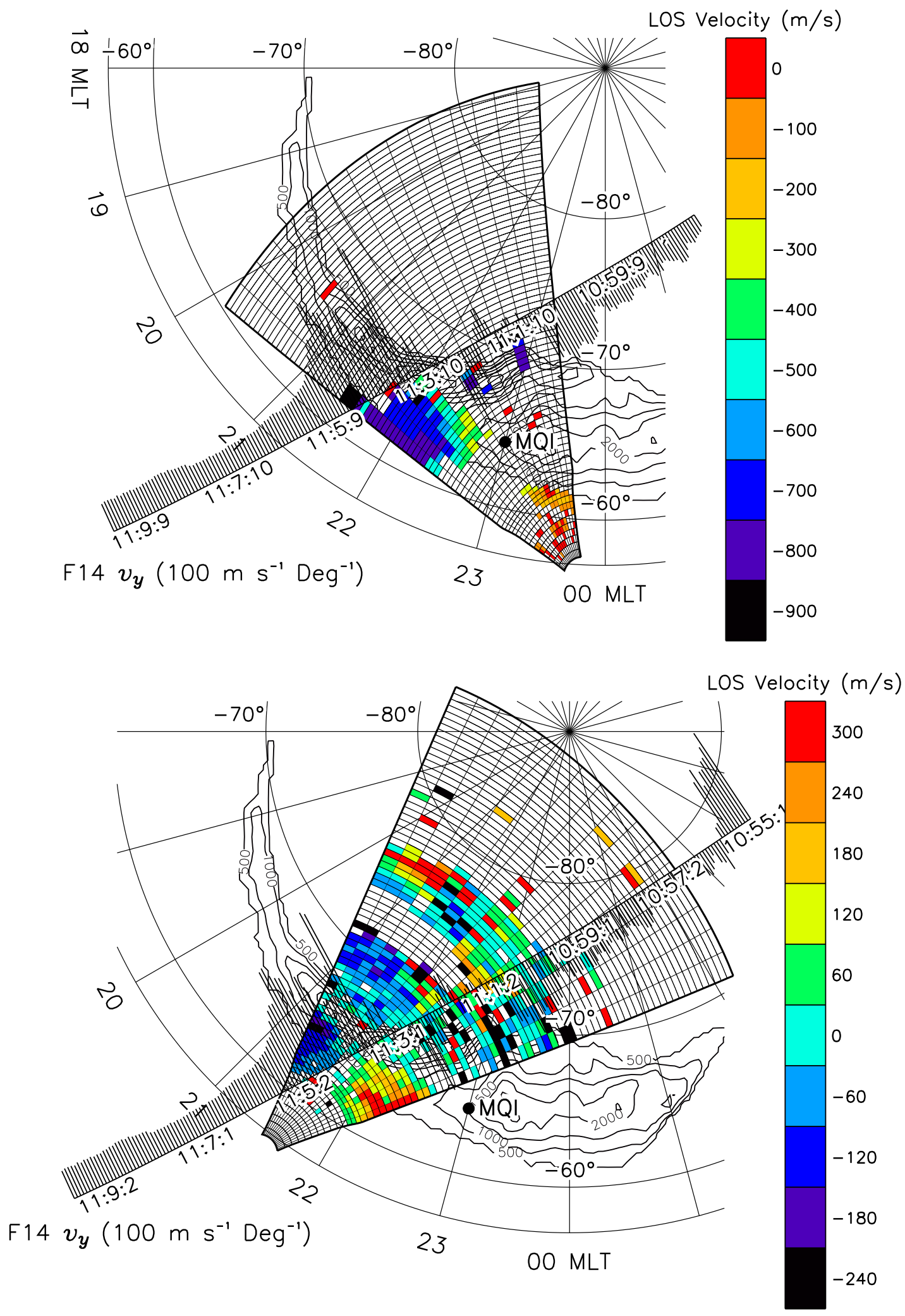

Fig. 5. (a) KGS radar observations of the LOS Doppler velocity measured during the full scan commencing at 11:03:59 UT on 30 November 2002. DMSP F14 measurements of ion drift velocity transverse to the satellite trajectory have been superimposed using a scale of $100 \mathrm{~m} \mathrm{~s}{ }^{-1}$ ${ }^{\circ} \Lambda^{-1}$. They were mapped to the Northern Hemisphere simply by inverting the magnetic latitudes. (b) TIGER radar observations of the same. 
in this region may also provide important clues about the formation and evolution of the AWFC and substorm.

The LOS velocity was often observed to increase in range from the radar. However, the actual Doppler shifts imparted to the backscattered radio waves is an integral of the Doppler shifts encountered along the ray path (Bennet, 1968; Dyson, 1975). The observed velocity profile can be inverted to infer the true velocity profile (Dyson et al., 2001). Although this is a second-order effect, it does imply the velocities at furthest ranges were significantly larger than observed, perhaps by $10 \%$ or more for the zonal looking beams.

F14 SSIES measurements of the transverse velocity, $V_{y}$, were superimposed in Fig. 5a. The F14 satellite was directly conjugate to the ionospheric scatter recorded by KGS near 11:04:02 UT. $V_{y}$ was large and westward in this conjugate region, having two main peaks, $786 \mathrm{~m} \mathrm{~s}^{-1}$ at $-62.0^{\circ} \Lambda$, and $990 \mathrm{~m} \mathrm{~s}^{-1}$ at $-65.6^{\circ} \Lambda$. However, $V_{y}$ was suppressed in the region of strongest FUV emission. A convection reversal boundary (CRB) signature was located near to $-68^{\circ} \Lambda$, aligned with the poleward edge of the auroral oval. $V_{y}$ also reversed in sign several times poleward of the FUV emissions, suggesting the presence of strong plasma circulation in proximity to the onset region. Further into the polar cap, the SSIES velocities were consistent with the expected antisunward flows.

TIGER observations (Fig. 5b) revealed substantial approaching LOS velocities $\left(>270 \mathrm{~m} \mathrm{~s}^{-1}\right)$ on beam 15 , and receding velocities $\left(<-210 \mathrm{~m} \mathrm{~s}^{-1}\right)$ on beam 0 , overlapping the equatorward limit of the FUV emissions. The largest LOS velocities were probably slightly higher in latitude on beam 0 than beam 15, suggesting a poleward tilt of the AWFC. Again, the main peak SSIES $V_{y}$ of $786 \mathrm{~m} \mathrm{~s}^{-1}$ at $-62.0^{\circ} \Lambda$ agreed with the location of the AWFC identified by TIGER. Poleward of the auroral oval, the TIGER LOS velocities were weak and receding $\left(>-150 \mathrm{~m} \mathrm{~s}^{-1}\right)$ on the western beams, and weaker and variable in sign on the eastern beams. The latter implies the presence of strong circulation in the flow pattern, as did the reversals in SSIES $V_{y}$.

All data sets suggest the presence of AWFC-type structure overlapping the equatorward edge of the auroral oval. The SSIES westward velocities observed during numerous DMSP passes on this evening were generally narrower and weaker near midnight (e.g. Fig. 5), and broader and stronger near dusk (e.g. Fig. 4b), suggesting that AWFCs "spread out" and strengthen toward dusk. They also suggest large receding velocities would sometimes be observed on imaginary beams pointing even further equatorward.

Finally, the ionospheric scatter and spectral widths (not shown) observed by KGS and TIGER tended to be absent or weaker at the ranges of peak FUV emission. Also, the ionospheric scatter observed by TIGER tended to be absent or weaker on the meridional beams at the latitude of the AWFC (e.g. Fig. 5b). As discussed by Parkinson et al. (2004a), the former is consistent with the tendency for precipitationenhanced Pedersen conductivity to suppress electric fields, irregularity production (Vickrey and Kelley, 1982), and spectral widths. The latter is consistent with the important role of primary gradient drift waves in the generation of $10-\mathrm{m}$ scale irregularities.

\subsection{Beam-swinging results}

The beam-swinging technique described by Ruohoniemi et al. (1989) assumes a uniform velocity component along magnetic L shells. Freeman et al. (1991) modelled the technique and found it was reasonably accurate. In the absence of dual radar observations, the beam-swinging technique was used here as a tool to help visualise the basic flow patterns implied by the observed Doppler shifts, but many of the small-scale features should not be believed. The LOS velocities recorded by radars in opposite hemispheres could be combined if it were not for uncertainties in the field-line mapping.

The TIGER observations were ideal for a beam-swinging analysis because the eastern- and western-most beams looked at oblique angles to the zonal flows. However, no beam-swinging results are presented for KGS because the western-most beams ( 0 to 4 ) looked along the axis of the AWFC and provided insufficient variation of Doppler shift with azimuth to work. Moreover, the eastern-most beams (12 to 15 ) recorded scatter from a separate high-latitude flow regime which corrupted estimates of the two-dimensional flow vectors for the AWFC.

Figure 6a shows the two-dimensional flow vectors estimated along TIGER beam 4 , the magnetic meridian pointing beam, during the interval, 07:30 to 11:00 UT. Figure $6 \mathrm{~b}$ shows the same for the interval, 11:00 to 14:30 UT. The results are separated in this way to maintain legibility of individual vectors and flow patterns. The vectors have been calculated using 5-min resolution, and the flow speeds have been colour-coded using increments of $100 \mathrm{~m} \mathrm{~s}^{-1}$. Note the isolated drifts $>1 \mathrm{~km} \mathrm{~s}^{-1}$ scattered throughout the plot may be erroneous.

Figure 6a reveals the initial, large (red) westward drifts during Substorm A interval, 08:10 to 09:10 UT (20 MLT), had a significant poleward component, as did the equatorward edge of the auroral oval (cf. Fig. 4a). The velocities tended to expand equatorward and increase in speed during this interval. The velocities ranged between $\sim 600$ and $1300 \mathrm{~m} \mathrm{~s}^{-1}$ within the AWFC, but these were probably under-estimated because the narrow AWFC was not aligned with $\mathrm{L}$ shells, a requirement of the beam-swinging analysis. The westward velocities found poleward of the AWFC represent return sunward flows in the afternoon convection cell. The speed of these flows were less than in the AWFC. There is also evidence for velocity enhancements (green to orange) expanding equatorward to the latitude of the AWFC. Near to 10:30 UT, shortly after the start of Substorm B, the flow speeds were suppressed (Provan et al., 2004).

Figure $6 \mathrm{~b}$ reveals the subsequent flows poleward of the AWFC were weak and erratic, but equatorward and eastward flows gradually developed, and were well defined beyond 13:00 UT. The westward flows within the AWFC had a weak poleward component after 11:00 UT ( 23 MLT), as did the equatorward edge of the auroral oval (Fig. 5b). They 

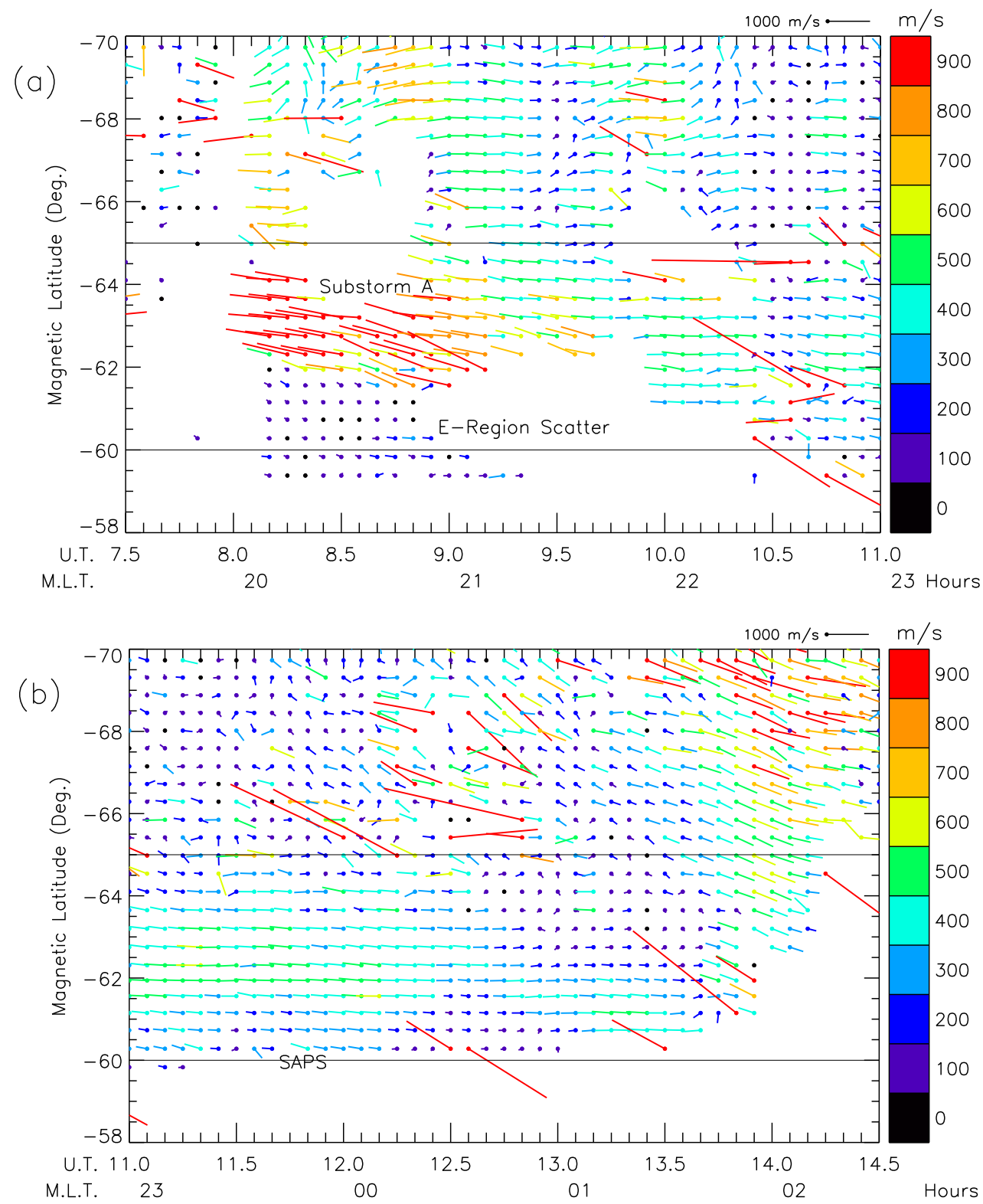

Fig. 6. (a) Two-dimensional flow vectors estimated along TIGER beam 4 using the beam-swinging technique at 5-min time resolution during 07:30 to 11:00 UT on 30 November 2002. The solid dots identify the time and latitude of the velocity estimate, and the lines point in the direction of the flows. Flows directed toward the right were eastward, and toward the bottom, equatorward. The flow speeds are colour coded from $<50 \mathrm{~m} \mathrm{~s}^{-1}$ (black) to $>850 \mathrm{~m} \mathrm{~s}^{-1}$ (red). Tick marks are at 5-min intervals. (b) The same as Fig. 6a except for the interval 11:00 to 14:30 UT on 30 November 2002.

were also fairly laminar over $\sim 4^{\circ} \Lambda$ of latitude, but the beamswinging technique may have broadened the latitudinal width (Parkinson et al., 2003). The poleward edge of the westward flows within the AWFC migrated equatorward between 12:35 and 13:40 UT ( $\sim 1$ MLT). The AWFC may have persisted at lower latitude in the dusk to midnight sector, but was no longer observed by radars that had rotated into the morning sector.

\subsection{HF radar observations: Time series representations}

Figure 7 presents a summary plot showing the conjugate HF radar observations occurring during 07:30 to 14:30 UT on 30 November 2002. The same substorm phases shown in Fig. 1 are superimposed, since we aim to reconcile changes in the character of the radar scatter with substorm activity. Part (a) is a range-time plot of the LOS Doppler velocity $\left(\mathrm{m} \mathrm{s}^{-1}\right)$ measured on KGS beam 2, whereas part (b) is the same measured on TIGER beam 14. The colour scale used for KGS velocities was shifted toward large negative values (i.e. receding toward the west), whereas the colour scale used 


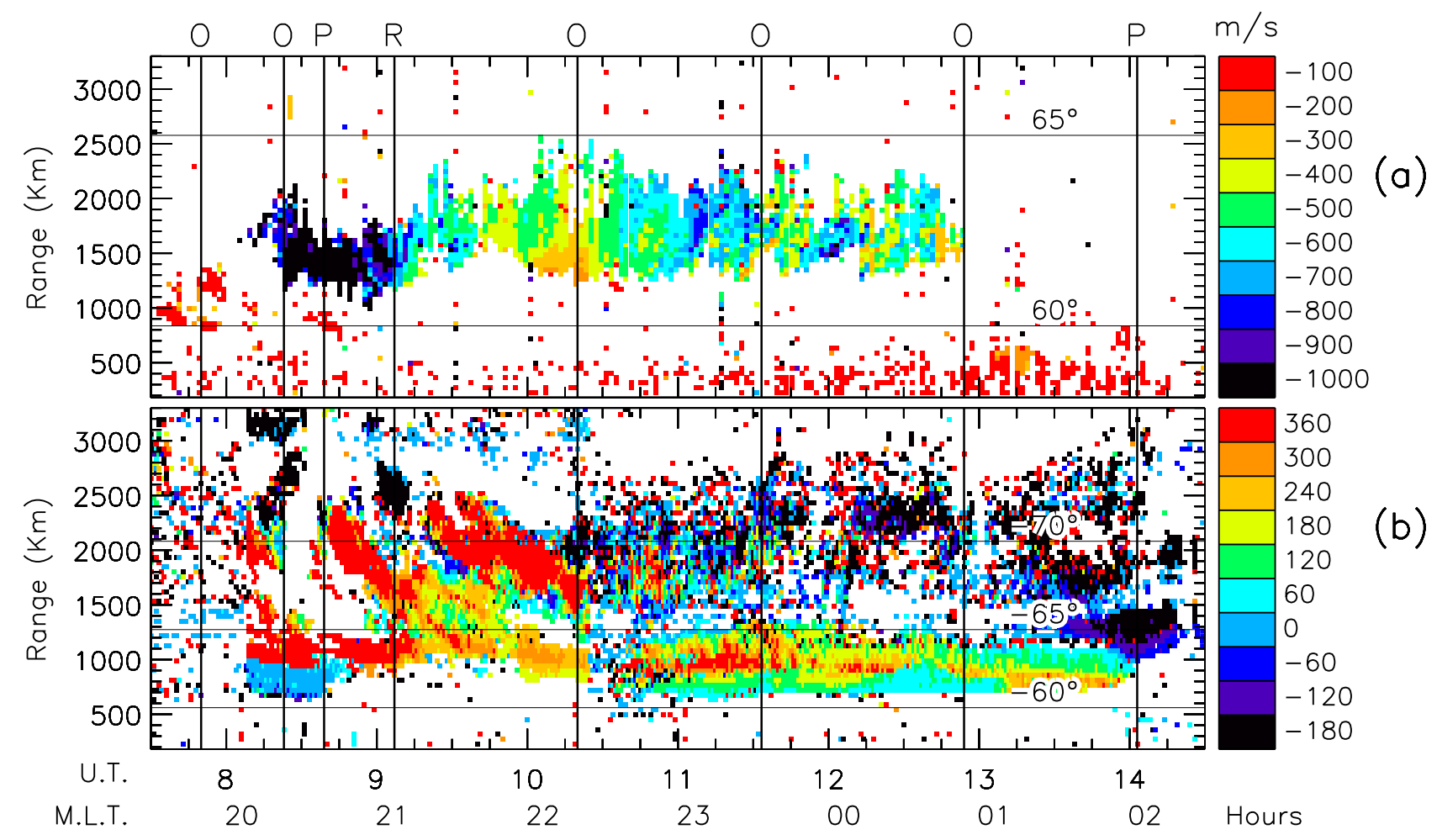

Fig. 7. (a) Range-time plot of the LOS Doppler velocity ( $\mathrm{m} \mathrm{s}^{-1}$ ) measured on King Salmon (KGS) beam 2 during 07:30 to 14:30 UT on 30 November 2002. (b) The same measured on TIGER beam 14. Thin vertical lines represent the same substorm phases shown in Fig. 1. Thin, black, horizontal lines represent magnetic latitudes and abscissas have tick marks at 15-min intervals of UT. Nominal values of MLT above MQI are also given.

for TIGER was shifted toward moderate positive values (i.e. approaching toward the east). The senses of these Doppler shifts are consistent with the presence of a persistent AWFC.

Observations recorded on KGS beam 2 are shown because they had the most continuous ionospheric scatter helping to define the occurrence of the AWFC in the Northern Hemisphere. This beam also pointed just poleward of magnetic west, and probably looked nearly directly along the AWFC (cf. Fig. 4a). Similarly, observations recorded on TIGER beam 14 are shown because it became a magnetic eastward beam at furthest ranges, and it had the best scatter helping to define the occurrence of the AWFC in the Southern Hemisphere.

By itself, the band of ionospheric scatter recorded on KGS beam 2 suggests the presence of an AWFC. However, the radar beam looked zonally, nearly along the length of the AWFC, so the width of the scatter in group range does not represent the width of the AWFC in latitude. Rather, it represents the width of the group range interval over which propagation conditions enabled detection of echoes from F-region irregularities. Hence, not withstanding the effects described by Bennet (1968) and Dyson (1975), variations in the LOS velocity with range better represent changes in velocity with longitude, whereas the time variation in LOS velocity at a fixed range gives a reasonable estimate of time variations in velocity within the flow channel.
The same arguments apply in the case of TIGER beam 14 observations, but to a much lesser extent because this beam was more oblique to the ionospheric flows. Hence the width in group range of scatter with large velocity was a better measure of the width of the AWFC in magnetic latitude, and temporal variation of velocity within the flow channel must be inferred by allowing for the oblique angle between the radar beam and AWFC.

Figure $7 \mathrm{a}$ shows the first hint of ionospheric scatter with large westward speed $>800 \mathrm{~m} \mathrm{~s}^{-1}$ (blue and black) was recorded on KGS beam 2 near $\sim 08: 13$ UT. The largest flow burst during the entire event with speeds $>1 \mathrm{~km} \mathrm{~s}^{-1}$ occurred during the subsequent interval $\sim 08: 13$ to 09:15 UT. As will be shown, the peak westward speed was $\sim 1500 \mathrm{~m} \mathrm{~s}^{-1}$ at 08:40 UT, near to the peak of expansion phase. This initial, intense flow burst was nearly synchronised with the most intense negative bay of Substorm A recorded by the MQI magnetometer (cf. Fig. 1). It was also coincident with the most intense part of Substorm A recorded by the Canadian magnetometer array.

Figure $7 \mathrm{~b}$ shows that large approaching speeds $>360 \mathrm{~m} \mathrm{~s}^{-1}$ (red) were observed by TIGER at low latitude $\left(-63^{\circ}\right.$ to $\left.-64^{\circ} \Lambda\right)$ during the interval 08:09 to 09:15 UT. Similar to the results for KGS beam 2, this initial flow burst was synchronised with the most intense negative bay of Substorm A, though it was detected $\sim 4$ min 
earlier. The AWFC suddenly appeared on TIGER beam 14 at 08:09 UT. This time corresponds to a change in the radar operating frequency from $\sim 9.7 \mathrm{MHz}$ to $\sim 17.8 \mathrm{MHz}$, made automatically by an algorithm designed to optimise the detection of ionospheric scatter (Hughes et al., 2002). The large change in operating frequency implies the AWFC may have existed prior to 08:09 UT, but the intervening plasma density was too large to favour its detection at $9.7 \mathrm{MHz}$.

Up to ten bands of scatter with large approaching speed $>360 \mathrm{~m} \mathrm{~s}^{-1}$ (red) were observed expanding equatorward, starting from $\sim-71^{\circ} \Lambda$ and lower latitude, during the interval 08:09 to 10:24 UT. WIC FUV images (e.g. Fig. 4b) suggest the poleward boundary of the auroral oval, or the OCB, was located far poleward of their origin. Some of the bands merged into the main band of scatter corresponding to the AWFC at $\sim-64^{\circ} \Lambda$. They reveal a sequence of narrow channels of intense westward drift expanding equatorward within the return sunward flow of the main dusk convection cell. So far, we have not been able to relate these equatorward expansions to changes in particle flux observed by the LANL spacecraft - they may represent substorm-related reconnection, or the Earthward migration of polarisation fields in the inner magnetosphere on closed field lines. The detailed relationship between these bands and auroral emissions needs investigation.

The change in the character of TIGER scatter at 10:25 UT was related to a change in the radar operating frequency from $\sim 14.7 \mathrm{MHz}$ to $9.7 \mathrm{MHz}$. Perhaps more irregularities were suddenly detected using $\sim 9.7 \mathrm{MHz}$ because of a change in propagation conditions triggered by a change in precipitation at 10:20 UT, the start of Substorm B (cf. Gauld et al., 2002). From this time onwards, the scatter at latitudes poleward of $-66^{\circ} \Lambda$ was dominated by echoes receding from the radar (blue and black), whereas the scatter at lower latitudes continued to be dominated by positive velocities (red). This is consistent with the observation of return sunward flows in the morning convection cell at higher latitude, a flow reversal boundary (FRB) located near $-66^{\circ} \Lambda$, and a persistent AWFC at lower latitude.

Figure $7 \mathrm{~b}$ shows a band of scatter with very low velocity $\sim 0 \mathrm{~m} \mathrm{~s}^{-1}$ (blue) was observed at near group ranges during 08:09 to 08:50 UT, just equatorward of the band of scatter revealing the initial flow burst (red). The two bands of scatter had different elevation angles and were separated by a sharp discontinuity. Combined, this suggests the nearer scatter was from E-region irregularities and the further scatter was from F-region irregularities. Large westward drifts in the AWFC may have extended further equatorward than propagation conditions permitted the radar to observe (cf. the SSIES $V_{y}$ observations, Fig. $4 \mathrm{~b}$ ).

After 10:25 UT, there was an artificially sharp cut-off in ionospheric scatter equatorward of group range $\sim 720 \mathrm{~km}$ or latitude $-61^{\circ} \Lambda$. This is probably because radio waves transmitted at higher elevation angles were no longer orthogonal to the magnetic field lines. Especially after 13:10 UT, an AWFC may have persisted at lower latitudes, but further equatorward than propagation conditions permitted the radar to observe. Again, SSIES observations suggest that large westward drifts did extend further equatorward. We conclude the radars observed the most poleward portion of the AWFC activity.

\subsection{Multi-beam time series representations}

A comparison of the results recorded on all 16 beams of both radars reveals more features relevant to the AWFC dynamics. Figure 8a shows the maximum LOS speed found within the latitude range $61^{\circ}$ to $65^{\circ} \Lambda$ for all 16 beams of the KGS radar. Part (b) shows the same except for TIGER. Again, the colour scale used for KGS velocities is shifted toward large negative values because of the large westward motions, especially on the more equatorward and zonal beams (0 to 4). Similarly, the colour scale used for TIGER is shifted toward large positive values because of the same underlying zonal motion, especially on the more equatorward and eastward beams (12 to 15). The LOS speeds reversed in sign on the westward-looking beams (0 to 3 ).

Figure 8a shows a peak in the LOS speed expanding equatorward, commencing on beam 14 near 07:50 UT, and reaching beam 1 at 08:22 UT. This equatorward expansion commenced simultaneously with the negative bay onset-like (O) signature observed by the MQI magnetometer at 07:50 UT. Ionospheric scatter with large receding Doppler velocities commenced as early as 07:58 UT on KGS beam 4, and the band of scatter signifying the AWFC did not disappear until 13:16 UT on KGS beam 0. These results extend the time interval over which the AWFC activity was directly observed.

Peak speeds observed by TIGER in the AWFC were not closely synchronised with the peak speeds observed by KGS. For example, the initial large flows observed by TIGER were centred near 08:36 UT, but not until 08:40 UT in KGS observations. The decrease in TIGER speeds centred near 10:28 UT may have been caused by particle-precipitation enhanced Pedersen conductivity, but a similar feature was not observed by KGS. Enhanced speeds were centred near 12:00 UT in KGS observations, but the TIGER speeds diminished at this time. Careful inspection of Fig. 7 reveals other discrepancies.

\subsection{Conjugacy of AWFCs}

Magnetic field lines are usually considered to be equipotentials, and thus, to first order, the AWFCs observed in opposite hemispheres should be the same. If the results for the two radars cannot be reconciled then anomalous field-aligned potential drops are needed to explain the different electric field observed at opposite ends of the same magnetic flux tube. Figure 9a shows peak speeds observed on KGS beam 2 (blue) and TIGER beam 14 (red) within the magnetic latitude range $61^{\circ}$ to $65^{\circ} \Lambda$ which includes the AWFC. Figure $9 \mathrm{~b}$ shows the magnetic latitudes corresponding to the group ranges of peak speeds identified in 9a, where the conjugate TIGER latitudes have been inverted to the Northern Hemisphere. 


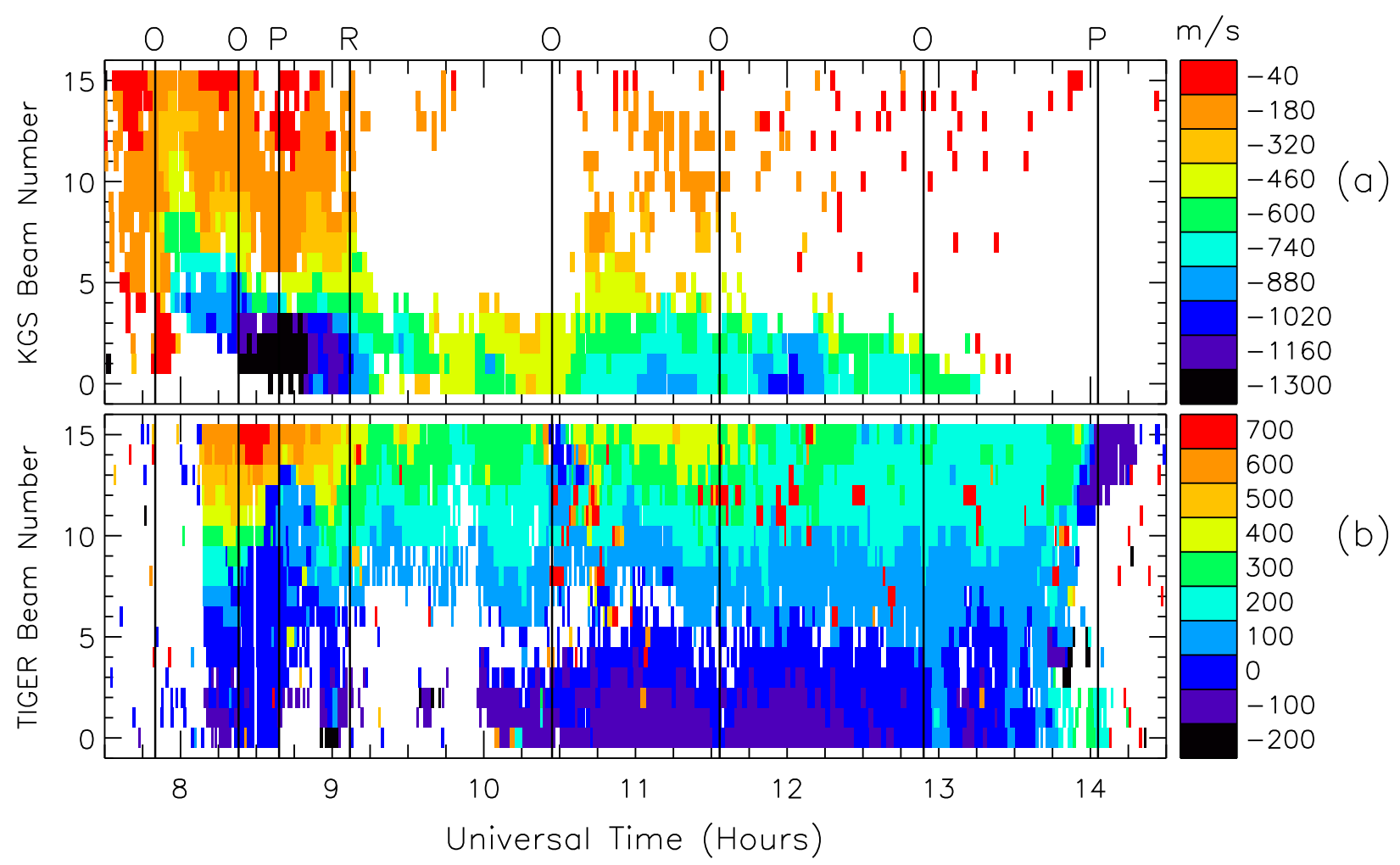

Fig. 8. (a) The maximum LOS speed found with the latitude range $61^{\circ}$ to $65^{\circ} \Lambda$ for all 16 beams of the KGS radar. For the lowest beam numbers (0 to 4$)$, this latitude range tended to select peak speeds within the scatter associated with the AWFC. (b) The same except for all 16 beams of the TIGER radar. Similarly, for the highest beam numbers (11 to 15), this latitude range tended to select peak speeds within the scatter associated with the AWFC.

Chisham and Freeman (2003a,b) used median filtering to reliably identify the spectral width boundary (SWB), an important feature in the radar data. Median filtering in space and time is an effective way to suppress measurement noise associated with inadequate signal-to-noise ratio (SNR), the radar pulse set, and the FITACF algorithm. In Fig. 9, the ranges of peak speeds were automatically identified using an algorithm requiring the detection of at least three ionospheric echoes with SNR $>3 \mathrm{~dB}$ during each integration. A median filter of dimension 3 was then applied prior to detecting the maxima (bold dots). The continuous curves are the results obtained after applying another median filter of dimension 3 , but now in the time domain. Despite the scatter, the final curves represent real trends in the data.

PJ/SAIDs are thought to be coherent structures extending over many hours of MLT, they are generally weaker and broader at dusk, and expand equatorward with MLT and converge in width with time (Anderson et al. 2001; Karlsson et al., 1998). An examination of full-scan data for our conjugate event (Figs. 4 and 5) suggests an orientation slightly poleward of magnetic west. However, it is very difficult determining the exact orientation of the AWFC without dual radar observations in the same hemisphere, thereby unaffected by uncertainties in the magnetic field line mapping.

Considering Fig. 4a, KGS beam 2 must have pointed roughly in the same direction of the velocities within the
AWFC. These LOS velocities can be re-interpreted as the peak westward speeds within the AWFC, but they must be an under-estimate because beam 2 probably pointed slightly poleward of the AWFC, and its beamwidth probably smeared over the fine-scale velocity structure. The probable angular difference is only $\sim 10^{\circ}$; hence the speeds shown in Fig. 8 were scaled up by the factor $\sec \left(10^{\circ}\right)$, or a mere $1.5 \%$. Even if the error in the direction were $20^{\circ}$, the velocities would only be $6.4 \%$ larger, still a relatively minor correction.

An examination of TIGER full-scan data for the present event suggests it was aligned with the equatorward edge of the auroral oval which was tilted slightly equatorward of geodetic west. TIGER beam 14 points $21.06^{\circ}$ to the east of the geodetic pole; hence the LOS speeds were scaled up by the factor cosec $\left(21.06^{\circ}\right)$, or $278 \%$. However, even if the angular difference between the AWFC and beam 14 were one beamwidth $\left(\sim 4^{\circ}\right)$ less, the scaling factor would decrease to $236 \%$. Clearly, the errors involved in scaling the TIGER speeds are large because of the way in which beam 14 transects the AWFC at oblique angles.

The results presented in Fig. 9a show our best estimates of variations in conjugate AWFC speeds in the Northern (blue) and Southern (red) Hemispheres. Both radars observed peak speeds of $\sim 1600 \mathrm{~m} \mathrm{~s}^{-1}$ and their is a surprising amount of resemblance between many of the short-term fluctuations. Overall, the major variations in speed observed in the North- 


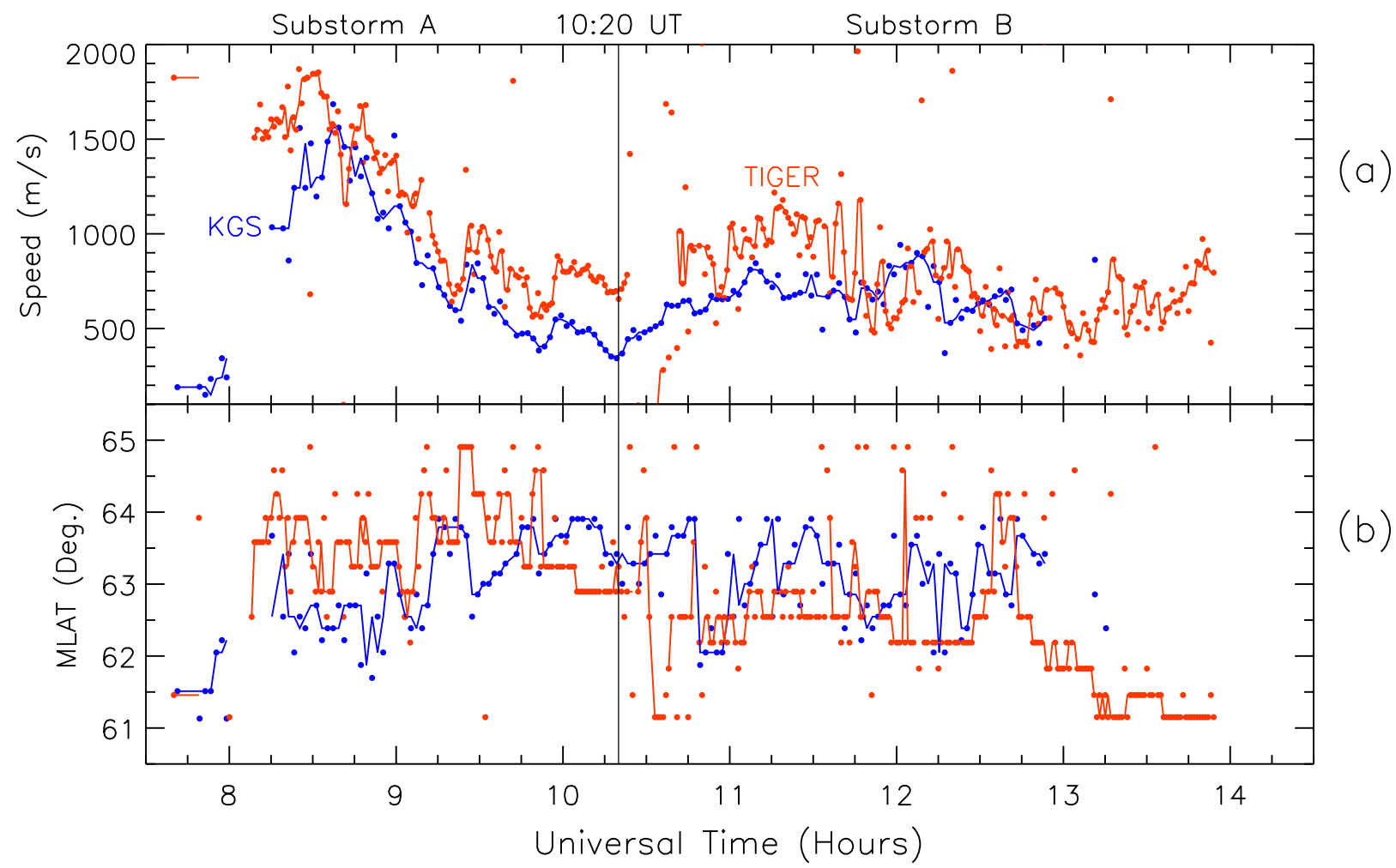

Fig. 9. (a) The maximum speeds identified within the latitude range $61^{\circ}$ to $65^{\circ} \Lambda$ along KGS beam 2 (blue) and TIGER beam 14 (red). This latitude range selects peak speeds within the scatter associated with the AWFCs (cf. Fig. 7). The speeds were scaled up to allow for difference between the orientation of the radar beams and the AWFC (see text). (b) The bold dots show the AACGM latitude of the corresponding group ranges of the results shown in (a). The continuous curves were obtained by applying a median filter of dimension 3 in the time domain.

ern and Southern Hemisphere were similar, lending support to the notion that magnetic field lines are equipotentials. Nevertheless, there were significant differences, and our results suggest the peak speeds were slightly larger in the flow channel observed in the Southern Hemisphere.

The KGS beam 2 speeds declined toward a minimum of $\sim 352 \mathrm{~m} \mathrm{~s}^{-1}$ at 10:18 UT, whence they gradually increased again, reaching a maximum of $\sim 882 \mathrm{~m} \mathrm{~s}^{-1}$ at 12:08 UT, before declining again. The increase in speed commencing near 10:18 UT was near to the start of Substorm B, and the time of maximum speed, 12:08 UT, was near to the last of three electron flux increases observed by LANL 1994-084 at 10:20, 11:33, and 12:09 UT (Table 1). However, more particle injections were subsequently observed, and the ground-based magnetometers showed the westward electrojet continued to intensify. AWFC activity may have continued to expand equatorward in the pre-midnight sector beyond 13:00 UT.

Figure $9 \mathrm{~b}$ shows the magnetic latitudes corresponding to the locations of peak speed within the AWFC in the Northern (blue) and Southern (red) Hemispheres. The results for KGS beam 2 and TIGER beam 14 nearly always agree within $\sim 1^{\circ} \Lambda$, but there were many fluctuations in the median filtered locations (continuous curves). However, many of the fluctuations were erroneous. For example, the equatorward jump in latitude at 10:32 UT is an artefact caused by changing propagation conditions and measurement noise. The ac- curacy of the results should be judged in the context of the actual LOS measurements shown in Fig. 7.

During 08:10 to 09:10 UT, the signature of the AWFC observed by TIGER was consistently $\sim 1^{\circ} \Lambda$ further poleward than observed by KGS. The latitudes gradually converged until 09:45 UT, whence the situation reversed. Between $\sim 09: 50$ to 12:34 UT, the signature of the AWFC observed by KGS tended to be located slightly poleward of that observed by TIGER. A poleward inflection in the location of the AWFC was observed by TIGER centred on 12:40 UT (cf. Fig. 7b). There was no change in the radar operating frequency at this time. The latitude of peak speed expanded equatorward between 12:40 and 13:13 UT, and then "saturated" at $-61^{\circ} \Lambda$ between 13:13 and 13:58 UT. The AWFC had expanded to the equatorward limit of where F-region scatter could be detected.

Disagreements between the two hemispheres are partly explained by temporal variations in the orientations of the AWFCs, latitudinal variations in their location (Fig. 9b), and measurement noise. There may have also been significant variations in the convolution between the beam and pulse widths with fine-scale velocity structure within the AWFCs. For example, a different velocity would be observed depending on whether a narrow spike in the velocity profile was located in the centre or the periphery of a $45-\mathrm{km}$ wide pulse. However, these factors do not explain all of the differences. 


\section{Discussion and conclusions}

Previous satellite observations have reported a 30-min delay between substorm onset and the occurrence of PJ/SAIDs (Anderson et al., 1993). Parkinson et al. (2003) analysed observations of an AWFC occurring on 27 February 2003, and found the event commenced near substorm onset, and rapidly decayed near the end of recovery phase. The AWFC and substorm activity was more complex on 30 November 2002, with LANL geosynchronous satellite and ground-based magnetometer data suggesting multiple onsets during two extended intervals of substorm activity. We referred to these intervals as "Substorm A" and "Substorm B."

There can be no doubt the AWFC activity reported here commenced before the recovery phase, and it probably commenced at substorm onset. For example, a peak in the velocity expanded equatorward, commencing on KGS beam 14 near 07:50 UT (Fig. 8a), an expansion onset signature of Substorm A. Large westward drift velocities probably occurred prior to their detection by TIGER at 08:09 UT. Echoes from an AWFC were probably not observed earlier simply because propagation conditions did not favour the detection of irregularities via 0.5 -hop propagation at the chosen operating frequency. We suspect that AWFC activity actually commenced near the time of the first particle injections detected by the LANL satellites shortly after $\sim 06: 45$ UT. As of yet, we have found no direct evidence of AWFCs commencing during the substorm growth phase.

At face value, the peak velocities within the AWFC (Fig. 9a) did not increase as the MQI negative bay deepened during Substorm B (Fig. 1). However, as previously explained, Figs. 7 and 9 suggest that beyond 13:13 UT, peak velocities within the AWFC had expanded equatorward of the preferred range gate for the detection of F-region echoes via 0.5 -hop propagation. The KGS and TIGER radars had rotated to past magnetic midnight ( $\sim 02 \mathrm{MLT})$, near the eastern limit of AWFC occurrence. A second, stronger AWFC may have developed at lower latitude, and at an earlier local time. A third radar located further to the west ( $\sim 22$ MLT) may have observed a more intense AWFC during Substorm B.

We conclude the AWFC activity probably commenced near substorm onset, and decayed near the end of recovery phase. Although the lack of continuity of the radar echoes in longitude, latitude, and time, make it difficult to be absolutely certain, other events we have examined support this view. As mentioned, there is a possibility the peak velocities within the AWFC occurred at lower latitude and later times, as the magnetospheric polarisation fields migrated closer to Earth. This might explain why intense PJ/SAIDs have been observed at lower latitude during the recovery phase. The KGS and TIGER radars are limited to observing AWFCs poleward of $\sim 62^{\circ} \Lambda$. Clearly, more SuperDARN radars must be deployed at lower latitudes than KGS and TIGER to determine whether AWFCs are the same as PJ/SAIDs.

We have compiled statistics on the occurrence of AWFCs observed by TIGER during the year 2000, and they suggest their occurrence rate is very similar to the occurrence rate of substorms (Parkinson et al., 2004b). AWFCs are often synchronised to negative bays in the geomagnetic $X$-component measured at MQI. All of our results suggest that AWFCs are a fundamental aspect of substorms. In fact, in terms of electric field enhancements, they are the dominant signature of substorms. They might even be another trigger for substorms.

Jayachandran et al. (2003) discussed two substorms, identifying POLAR UVI onset, GOES dipolarisation, and LANL particle injection times. The POLAR UVI onsets were in the pre-midnight ionosphere whereas the GOES and LANL observations were at geosynchronous orbit. It is interesting that the POLAR UVI onsets (ionospheric signatures) preceded the GOES dipolarisation and LANL particle injection times (magnetospheric signatures) by several minutes. The POLAR UVI onsets also occurred near the equatorward boundary of the ion auroral oval, exactly where AWFCs occur in TIGER observations.

Jayachandran et al. (2003) also found that dayside and polar cap convection velocities decreased at substorm onset, and hypothesised this was a consequence of current continuity: given constant Chapman Ferraro and magnetosheath currents, the Region 1 currents driving the polar cap convection must diminish when the substorm current wedge intensifies. We infer that a portion of the total electric potential difference must shift from across the polar cap to across AWFCs at substorm onset. Both of these results lend support to the fundamental role of AWFCs in substorms.

AWFCs are enhanced westward drifts observed at auroral and sub-auroral latitudes, but what distinguishes them from the enhanced return sunward flows within the main dusk convection cell? The answer is that AWFCs are the substorm-related structure within the return sunward flows driven by polarisation fields as opposed to magnetic reconnection, though reconnection may ultimately help to drive their formation.

The equi-potentials representing the return sunward flows in high-latitude convection models are smooth because they average over the AWFC structure that nearly always exists in this region. A cursory examination of DMSP SSIES data reveals profuse "spiky" velocity structure within the dusk sector auroral oval and sub-auroral ionosphere. Our HF backscatter radar observations reveal the coincident velocity peaks are confined within narrow channels, well equatorward of the convection reversal boundary. Whilst many of the transient flow bursts may be reconnection driven, the extended, persistent flow channels are an indication that polarisation fields also play an important role.

In the present event, TIGER observed a succession of westward velocity enhancements expanding equatorward from near $-71^{\circ} \Lambda$, equatorward of the expected ionospheric footprint of the open-closed magnetic field line boundary (Fig. 4b). Some of these velocity enhancements reached the latitude of the main AWFC. They imply the Earthward migration of radial electric field enhancements from within the open-closed field line boundary towards the inner edge of the 
central plasma sheet. These velocity enhancements may be the signatures of magnetic reconnection. However, theories of PJ/SAID formation (Anderson et al., 1993; De Keyser, 1999; Galperin 2002) imply the Earthward migration of polarisation fields in association with particle injection fronts (cf. Fig. 2). More comprehensive observations combined with better modelling will help clarify the relationship between episodic reconnection and the formation of persistent AWFCs. The proposed THEMIS mission will deploy a fleet of five spacecraft in the magnetotail, and may help to clarify this issue.

Importantly, the present radar observations were of coincident AWFC activity imbedded within the SAPS within magnetically conjugate locations. The results summarised in Fig. 9 suggest the variations in flow speed and channel location exhibited the same basic trends on longer time scales. However, the flow channel speeds were probably somewhat larger in the Southern Hemisphere (Fig. 9a), and a detailed examination of individual scans confirms the presence of systematic differences in magnetic latitude (Fig. 9b). What geophysical factors might help to explain the asymmetries summarised in Fig. 9?

The AACGM coordinate system does not include the effects of magnetospheric currents which change the Earth's magnetic field in complicated ways depending on the IMF history and substorm phase. Hence, in reality, a magnetic field line tagged as $65^{\circ} \Lambda$ in the Northern Hemisphere, may not necessarily map to the magnetic field line tagged as $65^{\circ} \Lambda$ in the Southern Hemisphere. The ever-changing effects of magnetospheric currents will be minor at mid-latitudes, but they become very significant at auroral and polar cap latitudes.

The Tsyganenko 96 model (Tsyganenko, 1995; Tsyganenko and Stern, 1996) was used to trace magnetic field lines from representative auroral latitudes to the GSM equatorial plane using IMF $B_{y}=10 \mathrm{nT}$ and $B_{z}=-5 \mathrm{nT}$. $B_{y}=10 \mathrm{nT}$ will exaggerate the $B_{y}$ positive effect applicable to the events on 30 November 2002. Figure 10 shows the GSM equatorial location of evening sector magnetic field lines with ionospheric latitudes $\pm 63^{\circ} \Lambda$ and $\pm 65^{\circ} \Lambda$. The corresponding magnetic flux tubes reside in the location where magnetotail stretching and subsequent dipolarisation events start to become important. The AACGM latitudes near $64^{\circ} \Lambda$ are not exactly conjugate, with the discrepancy rapidly increasing between $63^{\circ} \Lambda$ and $65^{\circ} \Lambda$. The magnetic field lines in the Southern Hemisphere map to greater radial distance in the equatorial plane. Hence a given potential drop across the flux tube in the equatorial plane will map to a narrower latitude range, and thus produce stronger electric fields, in the Southern Hemisphere. This agrees with our observation of stronger drifts within the AWFC observed in the Southern Hemisphere.

The $B_{y}$ component is well known to introduce asymmetries into the high-latitude dayside convection pattern (Cowley, 1981). The nightside convection pattern is also modified by $B_{y}$, and $B_{y}$ might also produce an asymmetry in the locations of conjugate AWFCs. Referring to Fig. 9b, the AWFC was $\sim 1^{\circ} \Lambda$ further poleward in the Southern Hemisphere dur-
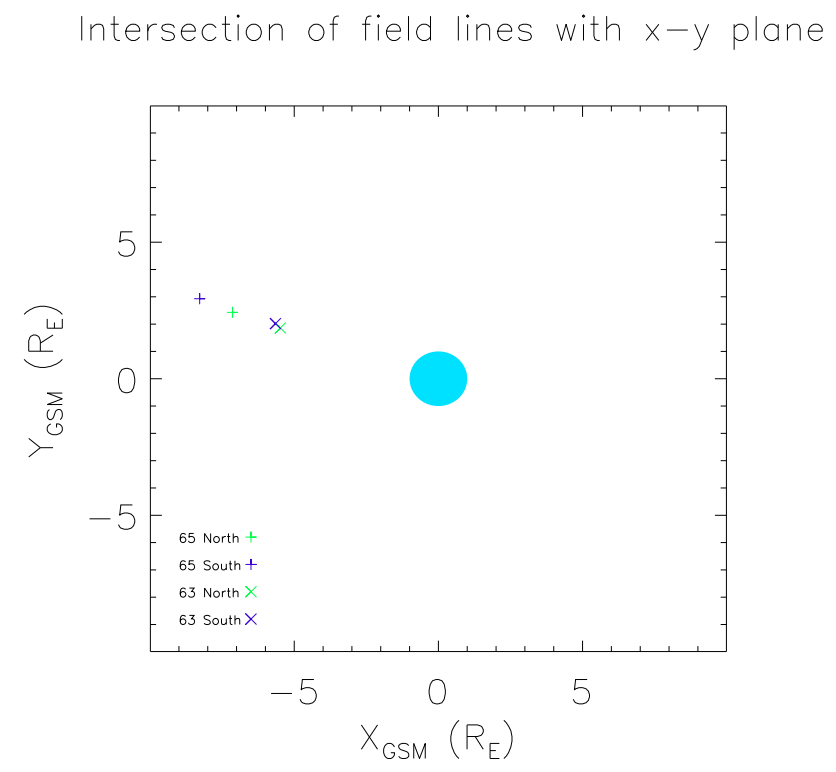

Fig. 10. Intersection of magnetic field lines with the GSM $X-Y$ plane at 12:00 UT on 30 November 2002. The field-line tracing was performed using the Tsyganenko 96 model with IMF $B_{y}=10 \mathrm{nT}$ and $B_{z}=-5 \mathrm{nT}$. The results are shown for evening sector (pre-midnight) magnetic field lines with ionospheric magnetic latitudes of $\pm 63^{\circ} \Lambda$ and $\pm 65^{\circ} \Lambda$.

ing $\sim 08: 09$ to 09:45 UT, and thereafter it was $\sim 1^{\circ} \Lambda$ further poleward in the Northern Hemisphere. $B_{y}$ was more positive when the AWFC was further poleward in the Southern Hemisphere, and then $B_{y}$ became more negative when the AWFC was further poleward in the Northern Hemisphere.

The preceding result needs further testing, but it is consistent with the statistical results of Provan et al. (2004). They calculated average SuperDARN convection velocities in the Northern Hemisphere versus substorm phase. The largest return sunward flows were observed just after substorm onset and equatorward of the convection reversal boundary when $B_{y}$ was negative. That is, AWFCs should be displaced further poleward in the Northern Hemisphere under $B_{y}$ negative conditions.

Our argument that magnetospheric currents distort the magnetic field line mapping probably does not explain all of the differences between the two AWFCs. Weimer et al. (1985) analysed electric field variations measured by the Dynamics Explorer (DE) 1 and 2 spacecraft located at altitudes above $4500 \mathrm{~km}$ and below $900 \mathrm{~km}$, respectively. Intervals when the two spacecraft were roughly conjugate were identified, and the electric fields were compared. When DE 1 and 2 were on field lines outside the auroral oval, a Fourier analysis of the variations showed the magnetic field lines were equipotentials across all spatial scales from large $(\sim 1000 \mathrm{~km})$ to small $(<100 \mathrm{~km})$. However, when the spacecraft were on field lines inside the auroral oval, the small-scale variations observed by DE 1 in the magnetosphere were 1-2 orders of magnitude stronger than those observed by DE 2 in the ionosphere. Their analysis showed that ionospheric Pedersen 
conductivity enhanced by particle-precipitation suppressed the transmission of electric field turbulence from the magnetosphere to the ionosphere. Their analysis was also consistent with earlier theory invoking anomalous field-aligned resistivity, potential drops, and currents, as required for auroral arcs.

Our conjugate AWFC observations can also be explained by the results of Weimer et al. (1985). The basic electric field variations at large spatial and temporal scales were in agreement (Fig. 9), excluding systematic differences due to distortion of the magnetic field mapping in proximity to the substorm dipolarisation region (Fig. 10). However, there were numerous differences at shorter spatial and temporal scales. These differences arose because the magnetic field lines were not equi-potentials in proximity to regions of precipitationenhanced Pedersen conductivity, such as the equatorward edge of the auroral oval. Indeed, this may be the underlying reason why magnetically conjugate observations have rarely shown impressive, detailed agreement.

Lastly, an important facet of the electrodynamics has thus far been ignored, namely the dynamics and chemistry of the neutral atmosphere. This is beyond the scope of the present HF radar study, but we might expect the frequent, daily occurrence of AWFC activity will drive a broad jet of westward neutral wind in proximity to the main ionospheric trough. The neutral wind may be enriched with molecular species, thereby enhancing the recombination rate (Vlasov and Kelley, 2003). This jet will penetrate to E-region altitudes during disturbed conditions, and persist during quiet conditions.

Acknowledgements. This work was supported by the Australian Research Council, the Australian Antarctic Science Advisory Council, and the Australian Academy of Sciences. During the course of this study J. A. Wild was supported by PPARC grant number PPA/G/O/2001/0014. R. Belian of Los Alamos National Laboratory (LANL) is thanked for making LANL geosynchronous electron data available. The DMSP particle detectors were designed by D. Hardy of AFRL, and data were obtained from JHU/APL. We thank D. Hardy, F. Rich, and P. Newell for its use. M. Hairston at the Center for Space Sciences at the University of Texas at Dallas is thanked for providing SSIES data. The IMAGE FUV investigation was supported by NASA through SwRI subcontract number 83820 at the University of California at Berkeley under contract number NAS596020. J. Samson at the University of Alberta is thanked for making Canadian magnetometer data available. Geoscience Australia is thanked for making MQI magnetometer data available. Finally, I. J. Coleman is thanked for making the Tsyganenko 96 magnetic field model calculations.

Topical Editor T. Pulkkinen thanks J. de Keyser for his help in evalauating this paper.

\section{References}

Anderson, P. C., Heelis, R. A., and Hanson, W. B.: The ionospheric signatures of rapid subauroral ion drifts, J. Geophys. Res., 96, 5785-5792, 1991.

Anderson, P. C., Hanson, W. B., Heelis, R. A., Craven, J. D., Baker, D. N., and Frank, L. A.: A proposed production model of rapid subauroral ion drifts and their relationship to substorm evolution, J. Geophys. Res., 98, 6069-6078, 1993.

Anderson, P. C., Carpenter, D. L., Tsuruda, K., Mukai, T., and Rich, F. J.: Multisatellite observations of rapid subauroral ion drifts, J. Geophys. Res., 106, 29 585-29 599, 2001.

André, R., Pinnock, M., Villain, J.-P., and Hanuise, C.: On the factors conditioning the Doppler spectral width determined from SuperDARN HF radars, Int. J. Geomag. Aeronomy, 2, 77-86, 2000.

Baker, D. N., Pulkkinen, T. I., Büchner, J., and Klimas, A. J.: Substorms: A global instability of the magnetosphere-ionosphere system, J. Geophys. Res., 104, 14 601-14 611, 1999.

Baker, K. B. and Wing, S.: A new magnetic coordinate system for conjugate studies of high latitudes, J. Geophys. Res., 94, 91399143, 1989.

Baker, K. B., Dudeney, J. R., and Greenwald, R. A., et. al.: HF radar signatures of the cusp and low-latitude boundary layer, J. Geophys. Res., 100, 7671-7695, 1995.

Bennett, J. A.: The ray theory of Doppler frequency shifts. Australian Journal of Physics, 21, 259-272, 1968.

Burke, W. J., Rubin, A. G., Maynard, N. C., Gentile, L. C., Sultan, P. J., Rich, F. J., Beaujardière, O. de La, Huang, C. Y., and Wilson, G. R.: Ionospheric disturbances observed by DMSP at middle to low latitudes during the magnetic storm of 4-6 June 1991, J. Geophys. Res., 105, 18 391-18 405, 2000.

Chisham, G. and Freeman, M. P.: A technique for accurately determining the cusp-region polar cap boundary using SuperDARN HF radar measurements, Ann. Geophys., 21, 1-14, 2003.

Chisham, G. and Freeman, M. P.: An investigation of latitudinal transitions in the SuperDARN Doppler spectral width parameter at different magnetic local times, Ann. Geophys., 22, 1187-1202, 2004 ,

SRef-ID: 1432-0576/ag/2004-22-1187.

Cowley, S. W. H. and Lockwood, M.: Excitation and decay of solar wind-driven flows in the magnetosphere-ionosphere system, Ann. Geophys., 10, 103-115, 1992.

De Keyser, J., Roth, M., and Lemaire, J.: The magnetospheric driver of subauroral ion drifts, Geophys. Res. Lett., 25, 1625-1628, 1998.

De Keyser, J.: Formation and evolution of subauroral ion drifts in the course of a substorm, J. Geophys. Res., 104, 12 339-12 349, 1999.

Dyson, P. L.: Relationships between the rate of change of phase path (Doppler shift) and angle of arrival. J. Atmos. Terr. Phys., 37, 1151-1154, 1975.

Dyson, P. L. and Devlin, J. C.: The Tasman International Geospace Environment Radar, The Physicist (The Australian Institute of Physics), 37, 48-53, 2000.

Dyson, P. L., Parkinson, M. L., Monselesan, D. P., and Morris, R. J.: On the determination of vertical profiles of ionospheric velocity from digital ionosonde measurements, ANARE reports, 146, 209-220, 2001.

Foster, J. C. and Burke, W. J.: SAPS, A new categorization for subauroral electric fields, EOS, Transactions, American Geophysical Union, 83(36), 393-394, 2002.

Freeman, M. P., Ruohoniemi, J. M., and Greenwald, R. A.: The determination of time-stationary 2-D convection patterns with single station radars, J. Geophys. Res., 96, 15 735-15 749, 1991.

Freeman, M. P., Southwood, D. J., Lester, M., Yeoman, T. K., and Reeves, G. D.: Substorm-associated radar auroral surges, J. Geophys. Res., 97, 12 173-12 185, 1992.

Frey, H. U., Mende, S. B., Carlson, C. W., Gerard, J.-C., Hubert, 
B., Spann, J., Gladstone, R., and Immel, T. J.: The electron and proton aurora as seen by IMAGE-FUV and FAST, Geophys. Res. Lett., 28, 1135-1138, 2001.

Galperin, Y. I., Ponomarev, V. N., and Zosimova, A. G.: Direct measurements of ion drift velocity in the upper ionosphere during a magnetic storm, 2. Results of measurements during the November 3, 1967, magnetic storm, Cosmic Res (Russian), 11, 283 292, 1973

Galperin, Y. I., Khalipov, V. L., and Filippov, V. M.: Signature of rapid subauroral ion drifts in the high-latitude ionosphere structure, Ann. Geophys., 4, 145-154, 1986.

Galperin, Y. I.: Polarization jet: Characteristics and a model, Ann. Geophys., 20, 391-404, 2002,

SRef-ID: 1432-0576/ag/2002-20-391.

Gauld, J. K., Yeoman, T. K., Davies, J. A., Milan, S. E., and Honary, F.: SuperDARN radar HF propagation and absorption response to the substorm expansion phase, Ann. Geophys., 20, 1631-1645, 2002,

SRef-ID: 1432-0576/ag/2002-20-1631.

Greenwald, R. A., Baker, K. B., Hutchins, R. A., and Hanuise, C.: An HF phased-array radar for studying small-scale structure in the high-latitude ionosphere, Radio Sci., 20, 63-79, 1985.

Greenwald, R. A., Baker, K. B., Dudeney, J. R., et. al.: DARN/SuperDARN: A global view of the dynamics of highlatitude convection, Space Sci. Rev., 71, 761-796, 1995.

Haerendel, G., Paschmann, G., Sckopke, N., Rosenbauer, H., and Hedgecock, P. C.: The frontside boundary layer of the magnetopause and the problem of reconnection, J. Geophys. Res., 83, 3195-3216, 1978.

Hardy, D. A., Schmitt, L. K., and Gussenhoven, M. S., et al. : Precipitating electron and ion detectors (SSJ/4) for the block 5-D/flights 6-10 DMSP satellites: Calibration and data presentation, Rep. AFGL-TR-84-0317, Air Force Geophys. Lab., Hanscom Air Force Base, Mass., 1984.

Henderson, M. G., Reeves, G. D., Belian, R. D., and Murphree, J. S.: Observations of magnetospheric substorms occurring with no apparent solar wind/IMF trigger, J. Geophys. Res., 101, 10773 $10791,1996$.

Huang, C-S., Foster, J. C., and Holt, J. M.: Westward plasma drift in the midlatitude ionospheric $\mathrm{F}$ region in the midnight-dawn sector, J. Geophys. Res., 106, 30 349-30 362, 2001.

Hughes, J. M., Bristow, W. A., Greenwald, R. A., and Barnes, R. J.: determining characteristics of HF communications links using SuperDARN, Ann. Geophys., 20, 1023-1030, 2002,

SRef-ID: 1432-0576/ag/2002-20-1023

Jayachandran, P. T., MacDougall, J. W., Donovan, E. F., Ruohoniemi, J. M., Liou, K., Moorcroft, D. R., and StMaurice, J.-P.: Substorm associated changes in the high-latitude ionospheric convection, Geophys. Res. Lett., 30(20), 2064, doi:10.1029/2003GL017497, 2003.

Karlsson, T., Marklund, G. T., and Blomberg, L. G.: Subauroral electric fields observed by the Freja satellite: A statistical study, J. Geophys. Res., 103, 4327-4341, 1998.

Lester, M., Milan, S. E., Besser, V., and Smith, R.: A case study of HF radar spectra and $630.0 \mathrm{~nm}$ auroral emission in the premidnight sector, Ann. Geophys., 19, 327-339, 2001,

SRef-ID: 1432-0576/ag/2001-19-327.

Lester, M., Parkinson, M. L., Wild, J. A., Milan, S. E., Nagai, T., McWilliams, K. A., Dyson, P. L., Singer, H. J., and Frey, H.: Simultaneous observations of ionospheric flow and tail reconnection signatures during the substorm expansion phase, accepted, 2005 .
Lui, A. T. Y.: Current controversies in magnetospheric physics, Reviews Geophys., 39, 535-563, 2001.

Mende, S. B., Frey, H. U., Lampton, M., Gerard, J.-C., Hubert, B., Fuselier, S., Spann, J., Gladstone, R., and Burch, J. L.: Global observations of proton and electron auroras in a substorm, Geophys. Res. Lett., 28, 1139-1142, 2001.

Milan, S. E., Davies, J. A., and Lester, M.: Coherent HF radar backscatter characteristics associated with auroral forms identified by incoherent radar techniques: a comparison of CUTLASS and EISCAT observations, J. Geophys. Res., 104, 22 591-22 604, 1999.

Newell, P. T., Feldstein, Y. I., Galperin, Y. I., and Meng, C.-I.: Morphology of nightside precipitation, J. Geophys. Res., 101, 10737-10748, 1996.

Ober, D. M., Horwitz, J. L., and Gallagher, D. L.: Formation of density troughs embedded in the outer plasma sphere by subauroral ion drift events, J. Geophys. Res., 102, 14 595-14 602, 1997.

Parkinson, M. L., Dyson, P. L., Pinnock, M., Devlin, J. C., Hairston, M. R., Yizengaw, E., and Wilkinson, P. J.: Signatures of the midnight open-closed magnetic field-line boundary during balanced dayside and nightside reconnection, Ann. Geophys., 20, 16171630, 2002,

SRef-ID: 1432-0576/ag/2002-20-1617.

Parkinson, M. L., Pinnock, M., Dyson, P. L., Ye, H., Devlin, J. C., and Hairston, M. R.: On the lifetime and extent of an auroral westward flow channel observed during a magnetospheric substorm, Ann. Geophys., 21, 893-913, 2003,

SRef-ID: 1432-0576/ag/2003-21-893.

Parkinson, M. L., Chisham, G., Pinnock, M., Dyson, P. L., and Devlin, J. C.: Magnetic local time, substorm, and particle precipitation-related variations in the behaviour of SuperDARN Doppler spectral widths, Ann. Geophys., 22, 4103-4122, 2004a, SRef-ID: 1432-0576/ag/2004-22-4103.

Parkinson, M. L., Dyson, P. L., and Pinnock, M.: The importance of auroral westward flow channels in substorm evolution, Submitted to Advances in Space Research, 2004b.

Provan, G., Lester, M., Mende, S. B., and Milan, S. E.: Statistical study of high-latitude plasma flow during magnetospheric substorms, Ann. Geophys., 22, 3607-3624, 2004,

SRef-ID: 1432-0576/ag/2004-22-3607.

Providakes, J. F., Kelley, M. C., and Swartz, W. E.: Radar and optical measurements of ionospheric processes associated with intense subauroral electric fields, J. Geophys. Res., 94, 5350-5366, 1989.

Rich, F. J., Burke, W. J., Kelley, M. C., and Smiddy, M.: Observations of field-aligned currents in association with strong convection electric fields at subauroral latitudes, J. Geophys. Res., 85, 2335-2340, 1980.

Ruohoniemi, J. M., Greenwald, R. A., Baker, K. B., Villain, J-P, Hanuise, C., and Kelly, J.: Mapping high-latitude plasma convection with coherent HF radars, J. Geophys. Res., 94, 13463 $13477,1989$.

Russell, C. T. and Elphic, R. C.: Initial ISEE magnetometer results: magnetopause observations. Space Sci. Rev., 22, 681-715, 1978.

Shand, B. A., Lester, M., and Yeoman, T. K.: Substorm associated radar auroral surges: a statistical study and a possible generation model, Ann. Geophys., 16, 441-449, 1998,

SRef-ID: 1432-0576/ag/1998-16-441.

Smiddy, M., Kelley, M. C., Burke, W., Rich, F., Sagalyn, R., Shuman, B., Hays, R., and Lai, S.: Intense poleward directed electric fields near the ionospheric projection of the plasmapause, Geophys. Res. Lett., 4, 543-546, 1977. 
Smith, C. W., L'Heureux, J., Ness, N. F., Acuna, M. H., Burlaga, L. F., and Scheifele J.: The ACE magnetic fields experiment, Space Sci. Rev., 86, 613-632, 1998.

Southwood, D. J.: The role of hot plasma in magnetospheric convection, J. Geophys. Res., 82, 5512-5520, 1977.

Southwood, D. J. and Wolf, R. A.: An assessment of the role of precipitation in magnetospheric convection, J. Geophys. Res., 83, 5227-5232, 1978.

Spiro, R. W., Heelis, R. A., and Hanson, W. B.: Rapid subauroral ion drifts observed by Atmospheric Explorer C, Geophys. Res. Lett., 6, 660-663, 1979.

Tsyganenko, N. A.: Modeling the Earth's magnetospheric magnetic field confined within a realistic magnetopause, J. Geophys. Res., 100, 5599-5612, 1995.

Tsyganenko, N. A. and Stern, D. P.: Modeling the global magnetic field of the large-scale Birkeland current systems, J. Geophys. Res., 101, 27 187-27 198, 1996.

Vickrey, J. F. and Kelley, M. C.: The effects of a conducting E layer on classical F region cross-field plasma diffusion, J. Geophys. Res., 87, 4461-4468, 1982.
Vlasov, M. N. and Kelley, M. C.: Modeling of the elctron density depletion in the storm-time trough on 20 April 1985, J. Atmos. Solar-Terr. Phys., 65, 211-217, 2003.

Weimer, D. R., Goertz, C. K., Gurnett, D. A., Maynard, N. C., and Burch, J. L.: Auroral zone electric fields from DE 1 and 2 at magnetic conjunctions, J. Geophys. Res., 90, 7479-7494, 1985.

Yeh, H.-C., Foster, J. C., Rich, F. J., and Swider, W.: Storm time electric field penetration observed at mid-latitude, J. Geophys. Res., 96, 5707-5721, 1991.

Yeoman, T. K., Lewis, R. V., Milan, S. E., and Watanabe, M.: An interhemispheric study of the ground magnetic and ionospheric electric fields during the substorm growth phase and expansion phase onset, J. Geophys. Res., 104, 14 867-14 877, 1999.

Yeoman, T. K., Wright, D. M., Stocker, A. J., and Jones, T. B.: An evaluation of range accuracy in Super Dual Auroral Radar overthe-horizon HF radar systems, Radio Sci., 36, 801-813, 2001. 